\title{
2007/68
}

Learning, hubris and corporate serial acquisitions

Nihat Aktas, Eric de Bodt, and Richard Roll 


\title{
CORE DISCUSSION PAPER
}

$2007 / 68$

\section{Learning, hubris and corporate serial acquisitions}

\author{
Nihat AKTAS $^{1}$, Eric DE BODT ${ }^{2}$ \\ and Richard ROLL ${ }^{3}$
}

September 2007

\begin{abstract}
Recent empirical research has shown that, from deal to deal, serial acquirers' cumulative abnormal returns (CAR) are declining. This has been most often attributed to CEOs hubris. We question this interpretation. Our theoretical analysis shows that (i) a declining CAR from deal to deal is not sufficient to reveal the presence of hubris, (ii) if CEOs are learning, economically motivated and rational, a declining CAR from deal to deal should be observed, (iii) predictions can be derived about the impact of learning and hubris on the time between successive deals and, finally, (iv) predictions about the CAR and about the time between successive deal trends lead to testable empirical hypotheses.
\end{abstract}

\footnotetext{
${ }^{1}$ CORE \& IAG, Université catholique de Louvain, Belgium. E-mail: nihat.aktas@uclouvain.be

${ }^{2}$ ESA, Université de Lille 2, France. E-mail: eric.debodt@uclouvain.be

${ }^{3}$ The Anderson School, University of California at Los Angeles, CA, USA.

E-mail: rroll@anderson.ucla.edu

We thank Sandra Betton, Michael Brennan, Estelle Cantillon, Bertrand Jacquillat, Michel Levasseur, Frédéric Lobez, John Talbott, Walter Torous and participants of the NFA 2005 Conference for the numerous suggestions, insights and constructive comments.

This paper presents research results of the Belgian Program on Interuniversity Poles of Attraction initiated by the Belgian State, Prime Minister's Office, Science Policy Programming. The scientific responsibility is assumed by the authors.
} 
For more than twenty years, an intensive debate has ensued about acquirers' motivations in mergers and acquisitions (M\&A). This is most likely due to early empirical results showing that acquirers' cumulative abnormal returns (CAR) around the announcement date are at best equal to zero or, worse, even negative (Jensen and Ruback, 1983). Why would firms undertake acquisitions if not to create value? Several arguments have been proposed in the literature to explain this puzzling result including the hubris hypothesis (Roll, 1986). ${ }^{1}$ Recent contributions help to resolve this puzzle to some extent. In particular, Moeller et al. (2004) by extending the analysis to a much larger sample of deals (more than 10,000), find clear evidence of a size effect: on average, acquirers' CAR are positive and significant (around 1.5\%) but, the larger the deal, the smaller (or more negative) the CAR becomes. Early studies, focusing only on large deals between listed companies, were affected from a sample selection bias.

However recent empirical studies raise a new, and perhaps even more challenging, puzzle: the CARs of serial acquirers are declining from deal to deal (e.g., Fuller et al., 2002; Billett and Qian, 2005; Conn et al., 2005; Croci, 2005; Ismail, 2006; Ahern, 2006) ${ }^{2}$. In most of the quoted references, the downward trend in CAR is interpreted as a clear evidence of hubris or of its development across the deal sequence (an exception is Ahern (2006)). Even if at first sight, the hubris argument appears appealing, this explanation is questionable within the framework of Roll (1986). Hubris, as defined originally, should be empirically associated with ex-post observable

\footnotetext{
${ }^{1}$ Without being exhaustive, other arguments put forward are the acquisition program effect (Schipper and Thompson, 1983; Malatesta and Thompson, 1985), the free cash-flow theory and the empire building motivation (Jensen, 1986).

${ }^{2}$ We provide detailed figures in the On-Line Appendix to this paper.
} 
overbidding and a significant probability of negative CAR. However, the above quoted papers report either significant positive or insignificant CAR across the deal sequence. ${ }^{3}$

Moreover, the hubris explanation is in sharp contrast with the claims of both the management literature and consulting firms. The management literature suggests that acquirers have a great potential to learn from experience (Hayward, 2002; Harding and Rovit, 2004). The professional press and consulting firms also emphasize that successful frequent acquirers are on a learning curve: "They often start with small, lower-risk deals and build capabilities in deal making. They institutionalize the processes and create a feedback loop to learn from mistakes" (Rovit et al., 2003). But how could declining acquirer CAR be consistent with any form of learning?

The above question is quite important. Indeed, if hubris really does explain the declining trend of CARs, concerns must be raised about both the selection process of CEOs and about corporate governance mechanisms. We propose an alternative and perhaps more palatable explanation. Our intuition is the following: if acquirers are learning, they improve their target selection and integration processing abilities from deal to deal. The risk associated with acquisitions decreases. As CEOs are risk averse, their bidding aggressiveness increases. They win the auction contests more often but the ex-post observed price paid also increases. The fraction of wealth retained by acquiring shareholders decreases, explaining the declining trend in CAR.

The learning and hubris based interpretation of the declining CAR trend rests on the central role of CEOs in the acquisition decision process. Personal characteristics of CEOs are indeed known to influence the managing style of firms (Bertrand and Schoar, 2003) and this is particularly true for large investment decisions such as M\&As. Even if smaller deals are supervised by low-level executives, hubris and/or learning could still affect behavior. So, to

\footnotetext{
${ }^{3}$ A notable exception is Billet and Qian (2005), where the authors, focusing only on large (over than 100 millions USD) M\&As between listed companies, report significant negative abnormal returns for the acquirers across the deal sequence.
} 
develop a theory of the CAR's pattern from deal to deal, we focus on decision maker's behavior. For convenience we refer to the decision maker as the CEO and it could actually be the CEO himself (for large deals), or the CFO (for intermediate deals) or some lower ranking executive (for small deals).

To better understand the CAR pattern from deal to deal, we develop a formal model of the CEO decision process and explore its consequences on observable bids, prices, the time between successive deals (TBD), and the CAR. Our main results are such as follow:

(i) a CAR declining trend should be observed for rational ${ }^{4}$ and economically motivated CEOs that learn from deal to deal. Learning enables the CEO to develop more precise valuations of successive targets; i.e., they become sequentially less risky, ceteris paribus. Taking into account CEO risk aversion, for a given level of expected value, this uncertainty reduction increases target valuation. This translates into higher bids, prices and, therefore a higher fraction of the wealth creation transferred to the target shareholders. This process generates a declining acquirer CAR trend during M\&A programs. In short, the lower the valuation risk, the higher the price the CEO is willing to pay.

(ii) learning also has implications for the TBD. Taking into consideration that the CEO riskadjusted valuation increases with learning (for a given level of expected value) and that the CEO bidding function (under quite general assumptions) is strictly increasing in his valuation, the probability that the CEO will win the auction also increases from deal attempt to deal attempt. Learning should lead therefore to a decreasing TBD.

These results indicate that a declining CAR trend is NOT necessarily due to hubris; it is also compatible with learning. As it is also pointed out in Conn et al. (2005) or Ahern (2006), a

\footnotetext{
${ }^{4}$ By a rational CEO, we mean a utility maximizing agent making decision on the basis of unbiased beliefs (see Section 1).
} 
declining CAR trend is in fact not specific to any given assumption. It could be due to hubris, to learning but also to a time-varying investment opportunity set (Klasa and Stegemoller (forthcoming)), budget constrained acquirers picking first good targets, or some form of mean reversion. Our model delivers however predictions not only about the CAR trend but also about the TBD. This allows us to derive implications that are more specific to the learning hypotheses and, therefore, open the door to empirical tests of the presence of learning in acquisition programs.

This paper is organized in 4 sections. The first section is dedicated to the study of the CEO's valuation of the target. Section 2 explores the CEO's bidding behavior and its implications for the price determination process. Section 3 is devoted to the formulation of empirical predictions. The final section summarizes and concludes.

\section{The Acquiring CEO's Valuation}

We first model the CEO's valuation process. Define the acquiring CEO's valuation of the target as the maximum price he is willing to pay for the target; (at any higher price, acquiring the target would negatively affect his current utility). We denote the CEO's target valuation $v$. For a risk averse CEO, this represents his certainty-equivalent. The CEO's valuation is the initial stage of the acquisition process. At this stage, potential competition is exogenous. The CEO has some perception of the potential behavior of competitors, once the acquisition attempt becomes public. The interaction between CEO bidding and competitors at a second stage will be explicitly analyzed in an auction based setup in Section 2. To avoid the analytic difficulty of target "picking" due to either limited funds or a redued opportunity set, we also assume that the CEO does not face a budget constraint. 


\subsection{Target Value and Expected Synergies}

In contrast to Shleifer and Vishny (2003), we assume that the capital markets are efficient in the sense that the market price is an unbiased estimate of the target firms' true economic value as a stand alone venture. Hence, acquisitions are not motivated by under-evaluation. Denote the target's market value $M V_{T}{ }^{5}$. The synergy potentially created by the merger is not perfectly known to the acquirer. It is a random variable (denoted $\tilde{s}_{t}$ ) and is defined as a proportion of $M V_{T}$. It includes all direct and indirect effects of the merger decision (e.g., the potential impact of this specific merger on the future continuation of the M\&A program). The target's market value in a completed acquisition becomes:

$$
\mathrm{MV}_{\mathrm{T}} \mid \text { acquisition }=\mathrm{MV}_{\mathrm{T}}\left(1+\widetilde{\mathrm{s}}_{\mathrm{t}}\right)
$$

Following the auction literature, $\tilde{s}_{t}$ must be understood as a private value to the acquirer and does not depend on the valuations of other potential acquirers. This implies that our setup applies more to strategic than financial acquisitions (see Bullow et al. (1999)). We assume that $\tilde{s}_{t}$ follows a Gaussian distribution $N\left(\mu_{s}, \sigma_{s}^{2}\right)$ where $\mu_{s}$ and $\sigma_{s}^{2}$ are respectively the expected synergy and the variance of the synergy. ${ }^{6}$ However, the CEO has limited information and perceives $N\left(\mu_{s}, \hat{\sigma}_{s, t}^{2}\right)$ at deal $t$, where $\hat{\sigma}_{s, t}^{2}$ represents the CEO perception of the uncertainty

\footnotetext{
${ }^{5}$ A summary of notations is provided in the On-Line Appendix to this paper.

${ }^{6}$ Since the distribution of $\tilde{s}_{t}$ is unbounded, this specification conceivably allows a negative market value. In the On-Line Appendix to this paper, we present an alternative specification, in which the market value of the target, conditional on a successful acquisition, is $M V_{T} \times e^{\tilde{s}_{t}}$ with $\tilde{s}_{t}$ normally distributed. Using the properties of the log-normal distribution, explicit solutions can be obtained but they are algebraically more messy and offer no additional insights.
} 
associated with synergy at that time. We use $\sim$ to indicate a random variable and ${ }^{\wedge}$ to indicate that a perception as opposed to a true parameter. Imperfect knowledge means that $\hat{\sigma}_{s, t}^{2} \geq \sigma_{s}$.

Two comments are worthwhile at this stage:

- the CEO is assumed to have unbiased anticipations (he knows $\mu_{s}$ ). This might appear unrealistic but it allows us to draw a clear distinction between rational CEOs and hubris infected CEOs (which will be analyzed in Section 3.3.) Hubris infected CEOs can indeed be characterized by biased priors.

- $\quad \mu_{s}$ is constant from deal to deal. This enables us to keep the investment opportunity set constant. Our objective is to isolate the effects of simple learning on CEO behavior and an evolving investment opportunity set would bring irrelevant complications.

\subsection{Learning}

Since firms (and their CEOs) often undertake acquisition programs (Schipper and Thompson, 1983; Malatesta and Thompson, 1985; Fuller et al., 2002) it seems reasonable that they should learn from each completed deal. We introduce learning explicitly in the form of a Bayesian updating process from deal to deal. Market reactions to each deal's announcement represent signals sent to the CEO about potential synergies, denoted $\tilde{\eta}_{t}$. They are assumed to be unbiased and follow a Gaussian distribution $N\left(\mu_{s}, \sigma_{\eta}^{2}\right)$, where $\sigma_{\eta}^{2}$ captures the precision of signals sent by the market (or the market's informativeness). ${ }^{7}$

Concerns could be raised about how reactions around past deal provide any information at all about a current deal attempt. This interesting question is studied by Hayward (2002). The author focuses on conditions that permit organizational learning to take place during serial acquisitions.

\footnotetext{
${ }^{7}$ The unbiased signal distribution is consistent with efficient markets.
} 
We assume that these conditions are fulfilled and that learning is possible. Using the Bayesian conjugate prior, the CEO posterior estimates of $\hat{\mu}_{s, t}$ and $\hat{\sigma}_{s, t}^{2}$ are:

$$
\begin{gathered}
\hat{\mu}_{s, t}=\frac{\left(\frac{1}{\hat{\sigma}_{s, 0}^{2}} \mu_{s}+\frac{1}{\sigma_{\eta}^{2}} \sum_{i=1}^{t-1} \eta_{i}\right)}{\frac{1}{\hat{\sigma}_{s, 0}^{2}}+(t-1) \frac{1}{\sigma_{\eta}^{2}}}=\frac{\left(\frac{1}{\hat{\sigma}_{s, 0}^{2}} \mu_{s}+\frac{1}{\sigma_{\eta}^{2}}(t-1) \mu_{s}\right)}{\frac{1}{\hat{\sigma}_{s, 0}^{2}}+(t-1) \frac{1}{\sigma_{\eta}^{2}}}=\mu_{s}, \\
\frac{1}{\hat{\sigma}_{s, t}^{2}}=\frac{1}{\hat{\sigma}_{s, 0}^{2}}+(t-1) \frac{1}{\sigma_{\eta}^{2}},
\end{gathered}
$$

where $N\left(\mu_{s}, \hat{\sigma}_{s, 0}^{2}\right)$ is the CEO prior and $(t-1)$ is the number of prior deals completed by the CEO. This setup could be extended to accommodate signals sent by rival acquirers without changing the nature of the argument.

For a CEO with unbiased anticipations, when the market is efficient and delivers signals centered on the population parameter, Equation (2) shows that the perception of the expected synergy is simply the population value. The variance of the posterior distribution in Equation (3) depends on the precision of the information sent to the CEO (the inverse of the signal variance $\sigma_{\eta}^{2}$ ). Note that as $\sigma_{\eta}^{2}$ grows, the signal precision falls and there is a smaller revision in the posterior precision; indeed, if the signal is totally non-informative, the posterior precision is unaltered from the prior. Also, for positive and finite values of $\sigma_{\eta}^{2}$, the posterior precision becomes monotonically smaller with the number of deals; asymptotically, the CEO learns perfectly about the synergy in prospective acquisitions.

\subsection{The CEO's Decision Problem}

Assumptions. To estimate the target valuation that maximizes his own expected utility, the CEO will take into account both the probability of the takeover being successful (defeating the 
best competitor's offer) and the probability of being penalized ex-post, due to disappointing realized synergies with respect to the acquisition price. As shown in Mitchell and Lehn (1990) and Lehn and Zhao (2006), potential dismissal is a real risk in practice. We model the CEO's decision problem while assuming:

- Bids and prices are strictly increasing in the CEO's valuation (The conditions supporting this assumption will be explored in Section 2.)

- The CEO wage contract is given and exogenous. The interaction between CEO wages and M\&A decisions would certainly be of great interest. Empirical evidence points toward a connection between the two (see, e.g., Datta et al., 2001) but this is beyond the scope of the present analysis;

- The form of ex-post penalty in case of disappointing synergies is also given and exogenous. In practice, it ranges from a one-shot financial penalty, through wage contract re-negotiation, up to being fired, depending on the corporate governance mechanisms in place and the degree of CEO entrenchment. For ease of exposition, we assume the penalty is dismissal; but any other form of sanction would leave our analysis unchanged.

Outcomes. Three outcomes are possible (see Figure 1):

- No Deal: a competitor's acquisition price is higher or the target successfully rebuffs the bid;

- Deal and CEO Retention: the bid price is sufficient for the acquisition and realized synergies are sufficient for the CEO to avoid being fired;

- Deal and CEO Dismissal: the acquisition is successful but the CEO is fired due to disappointing ex-post synergies.

Insert Figure 1 About Here 
To determine his expected utility, the CEO takes into account the probability of the above potential outcomes as well as the expected compensation in each case. We denote $\varphi_{S}$ the probability of a successful deal and $\varphi_{F}$ the probability of being fired. Note that both probabilities increase with the acquisition price, which depends on the bid, a function of the CEO's valuation; formally:

$$
\varphi_{i}=\varphi_{i}(p(\beta(v)) \text { for } i \in\{S, F\}
$$

where $p(),. \beta($.$) and v$ are, respectively, the price function, the bidding function and the CEO's valuation of the target. We mention this functional dependence explicitly only when necessary to avoid confusion and postpone to Section 2 the explicit analysis of $p($.$) and \beta($.$) .$

The two opposing forces at play in the CEO's decision problem give rise to the following conditions on the relations between the probabilities $\left(\varphi_{S}\right.$ and $\left.\varphi_{F}\right)$ and the target valuation:

- $\quad \varphi_{S}{ }^{\prime} \equiv \frac{\partial \varphi_{S}}{\partial v}>0$ : the probability of a successful deal increases with target valuation;

- $\quad \varphi_{F}{ }^{\prime} \equiv \frac{\partial \varphi_{S}}{\partial v}>0:$ the probability of dismissal increases also with target valuation

(remember that a higher valuation means a higher bid and, therefore, a higher paid price under our assumptions).

$C E O$ wage contract. We use $L, B+b M V_{T} \tilde{s}_{t}$ and $W$ to denote various components of the CEO’s compensation contract; viz.,

- $\quad W$ is the present value of the future compensation from existing activities;

- $\quad B+b M V_{T} \tilde{s}_{t}$ is the bonus in case of deal completion, composed of a fixed cash bonus $B$ and a variable component $b$, linked to the synergies;

- $\quad L$ denotes the loss in the event of dismissal.

$W, B, b$ and $L$ are known positive constants. 
This specification of the CEO compensation contract is in line with existing literature and with reality (see ao. Hall and Liebman (1998)), Datta et al., 2001, Hall and Murphy, 2002 and Grinstein and Hribar, 2004).

\subsection{Expected Utility Maximization}

We consider the case of a risk averse CEO (CEOs are known to be under-diversified (Hall and Murphy (2002), Becker (2006), Cai and Vijh (2006)). The expected utility of the CEO is given by:

$$
E(U)=\left(1-\varphi_{S}\right) U(W)+\varphi_{S}\left(1-\varphi_{F}\right) E\left(U\left(W+B+b M V_{T} \tilde{s}_{t}\right)\right)+\varphi_{S} \varphi_{F} U(W-L),
$$

where $U($.$) denotes the \mathrm{CEO}$ utility function. The CEO chooses $v$, the target valuation, in order to maximize his expected utility. We approximate it by a second-order Taylor series expansion around $W$. This leads to the following first order condition ${ }^{8}$ :

$$
\begin{aligned}
& {\left[\varphi_{S}{ }^{\prime}-\left(\varphi_{S} \varphi_{F}\right)^{\prime}\right]\left(B+b M V_{T} \mu_{s}\right)-\left(\varphi_{S} \varphi_{F}\right)^{\prime} L} \\
& -\gamma\left[\left(\varphi_{S}^{\prime}-\left(\varphi_{S} \varphi_{F}\right)^{\prime}\right) \frac{\left(b^{2} M V_{T}^{2} \hat{\sigma}_{s, t}^{2}+\left(B+b M V_{T} \mu_{s}\right)^{2}\right)}{2}+\left(\varphi_{S} \varphi_{F}\right)^{\prime} \frac{L^{2}}{2}\right]=0
\end{aligned}
$$

where $\gamma$ is the absolute risk aversion coefficient $-U^{\prime \prime}(W) / U^{\prime}(W)$.

\subsection{Uncertainty Specification}

In order to solve the model (to obtain a closed form formula for the expected utility maximizing valuation of the target), we need to specify the probabilities $\varphi_{S}$ and $\varphi_{F}$. Moreover, since these probability functions must be invertible, for convenience, we use uniform probability distributions. Although we specify $\varphi_{S}$ and $\varphi_{F}$ with respect to valuation, since it is the decision

\footnotetext{
${ }^{8}$ The derivation of Equation (6) is provided in the On-Line Appendix to this paper.
} 
variable of the $\mathrm{CEO}$, this is equivalent to specifying $\varphi_{S}$ and $\varphi_{F}$ with respect to prices. Prices are indeed (assumed to be) an increasing function of bids, and bids are (assumed to be) an increasing function of valuations (see Equation 4). ${ }^{9}$

The probability of success $\varphi_{S}$. Financial markets determine the initial value of the target $M V_{T}$, which essentially fixes the minimum bid price. This minimum price also provides us with a natural lower bound for $\varphi_{S}$. Define $V^{-}$as $V^{-}=\beta^{-1}\left(p^{-1}\left(M V_{T}\right)\right)$, this is to say the minimum target valuation such that the acquisition price would be $M V_{T}$. At $V^{-}$, the proposed acquisition price would be the target's current market value $\left(M V_{T}\right)$ and there would be no incentive for target shareholders to sell their shares, so any deal attempt would fail with probability one $\left(\varphi_{S}=0\right)$. The upper bound of $\varphi_{S}$ should be determined by a valuation such that the deal attempt will succeed with certainty. We denote the corresponding valuation level as $V_{S}^{+}$, equal to some multiple of $M V_{T} \cdot \varphi_{S}$ is uniformly distributed between $V^{-}$and $V_{S}^{+}$. For a given valuation $v$, the probability of success is therefore $\varphi_{S}=\left(v-V^{-}\right) /\left(V_{S}^{+}-V^{-}\right)$. Note that, as required, $\partial \varphi_{S} / \partial v$ is positive: the higher the valuation, the higher the probability of a successful deal.

The (conditional) probability of being dismissed $\varphi_{F}$. If CEO acquires the target, he risks being dismissed with probability $\varphi_{F}$. The target market value, $M V_{T}$, again provides a natural lower bound. Indeed, if $v$ is equal to $V^{-}$(which means that the valuation is such that the proposed acquisition price is the current target market value), there is no reason for the CEO to

\footnotetext{
${ }^{9}$ Since $\varphi_{S}$ and $\varphi_{F}$ are cumulative density functions, they are strictly increasing in their arguments. As $p($. and $\beta($.$) are also increasing in their arguments, \partial \varphi(p(\beta(v)) / \partial v$ has the same sign as $\partial \varphi(v) / \partial v$.
} 
be fired and $\varphi_{F}$ should be zero. ${ }^{10}$ Following the same logic as for $\varphi_{S}$, the upper bound of $\varphi_{F}$ is defined as a target valuation level so high that the price paid would lead, with probability one, to highly disappointing ex-post realized synergies relative to the acquisition price. The CEO would then be penalized (fired) with probability one. We denote this valuation level $V_{F}^{+}$. The probability of being fired is therefore uniformly distributed between $V^{-}$and $V_{F}^{+}$and equal to $\varphi_{F}=\left(v-V^{-}\right) /\left(V_{F}^{+}-V^{-}\right)$. We note that, as expected, $\partial \varphi_{F} / \partial v$ is positive: the higher the valuation, the higher the probability of being fired.

Classical equilibrium arguments show that $V_{F}^{+}$must be equal to $V_{S}^{+} \cdot{ }^{11}$ We can therefore explicitly relate $V_{F}^{+}$and $V_{S}^{+}$to some multiple of the target market value $M V_{T}$. We denote it $\theta$ : $V_{F}^{+}=V_{S}^{+}=V^{+}=\beta^{-1}\left(p^{-1}\left(\theta M V_{T}\right)\right)$

The unconditional probabilities. The probabilities of missing out on the deal, doing the deal and not being fired and doing the deal and being fired are respectively $\left(1-\varphi_{S}\right), \varphi_{S}\left(1-\varphi_{F}\right)$ and $\varphi_{S} \varphi_{F}$ (see Figure 2).

- $\quad\left(1-\varphi_{S}\right)=\frac{V^{+}-v}{V^{+}-V^{-}}$, the probability of missing out on the deal decreases linearly as $v$ increases (see Figure 2, Panel A);

- $\left(\varphi_{S}\left(1-\varphi_{F}\right)\right)=\left(\frac{v-V^{-}}{V^{+}-V^{-}}\right)\left(\frac{V^{+}-v}{V^{+}-V^{-}}\right)$, the probability doing the deal and not being fired is a concave function (see Figure 2, Panel B). When $v$ is close to $V^{-}$(no premium

\footnotetext{
${ }^{10}$ It could be argued that if the CEO has wasted a lot of his time and the time of others on valuing the deal, only to come up with the market value, maybe he should be fired for being wasteful. We abstract here from this complication for ease of exposition.

${ }^{11}$ The argument is provided in the On-Line Appendix to this paper.
} 
over the prevailing market price), increasing $v$ has a strong impact on the probability of doing the deal and not being fired. When $v$ is high, the probability of doing the deal (the sum of $\left(\varphi_{S} \varphi_{F}\right)$ and $\left.\varphi_{S}\left(1-\varphi_{F}\right)\right)$ still increases but the probability of being fired eventually dominates;

- $\quad\left(\varphi_{S} \varphi_{F}\right)=\left(\frac{v-V^{-}}{V^{+}-V^{-}}\right)^{2}$, the probability of being fired (given that the deal attempt has succeeded) is convex (see Figure 2, Panel C). For high $v$ the increase in the probability of being fired becomes significant. This captures the intuition that the corporate governance system (either internal or external) comes into play as a last resort mechanism. The CEO risks dismissal when the deal brings wealth destruction for bidder shareholders; but even below that extreme, dismissal is possible simply because the acquisition price is excessive relative to the realized synergies ex post. This property of our specification is consistent with the empirical results provided by Mitchell and Lehn (1990) and Lehn and Zhao (2006).

Insert Figure 2 About Here

\subsection{Target valuation}

Using the definition of $\varphi_{S}$ and $\varphi_{F}$, we can now solve the model. This results in our first proposition.

PROPOSITION 1. CEO's valuation of the target

Under the assumptions of Sections 1.1 to 1.5, which can be summarized as CEO risk aversion, uniformly distributed probability of being penalized in case of disappointing ex-post realized synergies relative to the acquisition price and exogenous competition, a linear wage contract, 
Bayesian learning based on previous deal experience and efficient financial markets, the CEO's reservation valuation is:

$$
\frac{v^{*}-V^{-}}{V^{+}-V^{-}}=\frac{1}{2} \frac{\left(B+b M V_{T} \mu_{s}-\gamma / 2\left(B+b M V_{T} \mu_{s}\right)^{2}\right)-\gamma / 2 b^{2} M V_{T}^{2} \hat{\sigma}_{s, t}^{2}}{\left(\left(B+b M V_{T} \mu_{s}-\gamma / 2\left(B+b M V_{T} \mu_{s}\right)^{2}\right)-\gamma / 2 b^{2} M V_{T}^{2} \hat{\sigma}_{s, t}^{2}\right)+\left(L+\gamma / 2 L^{2}\right)} . \text { (7) }
$$

The derivation of Proposition 1 is given in the On-Line Appendix to this paper.

Proposition 1 is a key to understanding the effect of learning on the CEO's decision process: it connects the CEO's valuation of the target (the maximum price he is willing to pay or his certainty-equivalent) to his risk aversion $(\gamma)$, expected synergies $\left(\mu_{s}\right)$ and his perception of the risk associated with synergies $\left(\hat{\sigma}_{s, t}^{2}\right)$. Equations (2) and (3) display the Bayesian updating process used by the CEO to incorporate signals sent by the market. So, the combination of Proposition 1 and Equations (2) and (3) represent tools for exploring the learning mechanism. To use them fully, we must now establish the links between the CEO valuation, his bidding function and his offering price function (up to now, we have simply assumed that these functions are strictly increasing in his valuation). To interpret Proposition 1, we note that $\left(B+b M V_{T} \mu_{s}-\gamma / 2\left(B+b M V_{T} \mu_{s}\right)^{2}-\gamma / 2 b^{2} M V_{T}^{2} \hat{\sigma}_{s, t}^{2}\right)$ is the risk adjusted bonus and $\left(L+\gamma / 2 L^{2}\right)$ is the risk adjusted loss. We also note that the risk adjusted bonus must positive at $v^{*} .^{12}$

\footnotetext{
${ }^{12}$ The arguments are provided in the On-Line Appendix to this paper.
} 


\subsection{Determinants of the CEO's valuation}

The CEO's valuation of the target and the perceived synergies are connected through the CEO's wage contract. The study of the relation between the CEO's valuation and the expected bonus and its variance allows us to derive the following results ${ }^{13}$ :

- $\quad$ for $0 \leq\left(B+b M V_{T} \mu_{s}\right)<1 / \gamma$ :

$$
\frac{\partial v^{*}}{\partial\left(B+b M V_{T} \mu_{s}\right)}>0
$$

- for $1 / \gamma<\left(B+b M V_{T} \mu_{s}\right)<(2 / \gamma)-\left(b^{2} M V_{T}^{2} \hat{\sigma}_{s,}^{2} /\left(B+b M V_{T} \mu_{s}\right)\right)$ :

$$
\frac{\partial v^{*}}{\partial\left(B+b M V_{T} \mu_{s}\right)}<0
$$

- and

$$
\frac{\partial v^{*}}{\partial b^{2} M V_{T}^{2} \hat{\sigma}_{s, t}^{2}}<0
$$

Equation (8) shows that, for $\left(B+b M V_{T} \mu_{s}\right)$ between 0 and $1 / \gamma, \partial v * / \partial\left(B+b M V_{T} \mu_{s}\right)$ is positive. An increase in the expected bonus leads to an increase in the CEO's reservation value. For $\left(B+b M V_{T} \mu_{s}\right)$ between $1 / \gamma$ and $(2 / \gamma)-\left(b^{2} M V_{T}^{2} \hat{\sigma}_{s, t}^{2} /\left(B+b M V_{T} \mu_{s}\right)\right)$, Equation (8') shows that the derivative is negative. This second situation might seem strange as an increase in the expected bonus could lead to a decrease in the CEO's reservation value. Such a possibility is a consequence of the convexity of $\varphi_{S} \varphi_{F}$, depicted in Figure 2 - Panel C. A high expected bonus combined with a low bonus variance dramatically increases the CEO's loss in the event of dismissal. Rather than vigorously pursuing the deal, the CEO responds by reducing the risk of

\footnotetext{
${ }^{13}$ The derivation is provided in the On-Line Appendix to this paper.
} 
being fired. In short, he has more to lose than to win (a similar argument is used by Barro (2006) to explain the equity premium puzzle). Such behavior is consistent with (internal or external) corporate control mechanisms that become more vigorous after value destruction (the unconditional probability of dismissal is convex with respect to the premium). Equation (9) shows that an increase in the (perceived) variance of the expected bonus leads to a decrease in the CEO's reservation value.

\section{Bidding and Buying the Target}

The previous section derived the CEO's valuation for the target. Valuations are however not observable as such. They are one of the main drivers of decisions but only the decisions themselves are observable. Within the M\&A context, the CEO's decision is the bid chosen in the attempt to acquire the target. Hence, we have to associate bids with valuations. This is however only an intermediate step. The ex post observable acquisition price will only emerge after bids have been confronted with rival bids and target shareholders reactions. The acquisition price essentially determines whatever wealth is created or destroyed for the bidding firm's shareholders. This section is dedicated to filling in the details between valuations, bids and expost observable prices.

When talking about the M\&A market, most often, large and highly publicized takeover contests come into mind. It is by reference to these cases that target acquisitions have most often been modeled as ascending auctions (see Bullow et al. (1999) or Betton et al. (2005)), in which a set of bidders compete to acquire a target, putting increasing bids on the table until all but one bidders quit. Under some restrictive assumptions (independent private valuations, quasi-linear payoffs, risk-neutral bidders), the Myerson's lemma holds (see Theorem 3.3 in Milgrom (2004)) and the ascending auction is revenue and pay-off equivalent to the second best price auction, which simplifies greatly the analysis. But public tender offers represent only one form taken by M\&A operations and, even if they are frequently very large deals, they represent a minority of 
cases. Schwert (2000) reports 763 tender offers out of 2,346 deals (33\%) during the period 19751996. Hostile bids are even less frequent. Andrade et al (2001), studying the period 1973-1998, report a percentage of hostile bids varying from 4\% (1990-1998) to 14.3\% (1980-1989).

How then are firms sold in the remaining cases? Boone and Mulherin (2007) report new and interesting results. The authors study a sample of 400 acquisitions from the nineties. Using data from SEC merger documents, they show that half of the targets were auctioned among multiple bidders and that the remaining half were sold through a direct negotiation between the parties. Hansen (2001) studies in detail the process with which firms are auctioned by financial intermediaries; a key difference from tender offers is frequent use of a sealed-bid first price auction. In contrast, for direct negotiation acquisitions, there is no direct competition. To sum-up, there are at least three distinct forms of M\&A deals: public tender offers, private auctions organized by financial intermediaries and direct negotiation between the parties. This section is devoted to the bidding and pricing implications of each type. The three most important issues are:

- CEO risk-aversion;

- Acquirers' asymmetry: Section 1 models how learning affects private valuations of the target. But learning comes from experience accumulated with previous deals and previous deals are publicly known. Therefore, when potential acquirers compete to buy a target, they know something about the historical records of each other. This implies an asymmetry in target valuations. In ascending auctions or first price sealed-bid auctions, this asymmetry is presumably taken into account by rational bidders. Asymmetry among potential acquirers' is explicitly modeled in Povel and Singh (2006), where the authors establish how targets should optimally sell themselves in such a framework. Complementing the results of Maskin and Riley (2000), Aroamena and Cantillon (2004) provides key insight about expected revues in first and second prices asymmetric auctions. 
- positive correlation of acquirers' valuations: a major empirical phenomenon about M\&As is their appearance in waves (see, e.g., Mitchell and Mulherin, 1996). It has been argued that it could be due to systematic mis-valuations in financial markets (Shleifer and Vishny, 2003) or to common market or industry wide shocks (Harford, 2005). Common shocks are a clear source of positive correlation between synergies potentially implemented by acquirers.

Having identified the key features to take into account, we are led to Proposition 2 below. Note that the analysis is based on the Bayesian Nash equilibrium concept and the Harsanyi coherence doctrine.

\section{PROPOSITION 2. Bidding and price functions}

Auctions. Under the assumptions of risk averse CEOs (with monotonic and log supermodular utility functions), asymmetric valuation distributions, positively correlated valuations and competition limited to two acquirers, the equilibrium bidding and price functions in tender offers and private auctions are strictly increasing in the valuation of the winning CEO. In both cases, at equilibrium, ex-post observable prices are increasing in valuation. In the case of private auctions, the results hold under the assumption of conditional stochastic dominance of the valuation distribution of the learning bidder over the other bidders.

Bargaining. Under the assumptions of a risk averse acquirer CEO (with a monotonic and log supermodular utility function) and a target with random positively correlated reserve price, the equilibrium bidding and price functions are strictly increasing in the CEO's reservation value.

The proofs are given in the One-Line Appendix to this paper.

\section{Ex-post Observable Implications}

This third section is devoted to the observable consequences of Propositions 1 and 2. The first issue concerns the effect of learning on expected profits of the acquirer. Expected profits are the product of two terms: 
(i) the wealth effect of the deal conditional on doing the deal (the value of the good in the case of winning the auction);

(ii) the probability of buying the target (the probability of winning the auction).

As emphasized in Section 1, learning is the source of asymmetry between bidders. Analyzing the effect of learning on expect profits amounts therefore to analyzing the effects of asymmetry on the equilibrium expected profits of bidders. Cantillon (forthcoming) has shown, extending the analysis of Maskin and Riley (2000), that asymmetry between bidders increases the strong bidder's expected profits (decreases the seller expected revenues). The intuition behind this result is the fact that asymmetry reduces the pressure of competition among bidders, allowing the winner to keep a higher fraction of its valuation. Applied to our problem, this result, means that learning increases the CEOs expected profits in equilibrium.

But expected profits are not observable. We only observe indirectly its two components:

- wealth effect conditional on doing deals: since deals are publicly announced for listed acquirers, market reactions are typically available. Assuming that the probability of deal completion is high once the deal has been announced (which is the case for most deals, particularly small ones), this is the investors' estimate of the wealth effect associated with the deal. Note however that the availability of bids and premiums over the target's value is far more limited. Among difficulties are the complexity of payments (e.g., a package containing stock, cash and other contingent claims) and the paucity of information about private targets. Perhaps these empirical constraints explain why most recent large sample studies focus on acquirers' CARs. ${ }^{14}$

- the probability of buying the target: contrary to CAR, this second component of the CEO expected profits is not observable. Unsuccessful deal attempts are (mostly) empirically

\footnotetext{
${ }^{14}$ One exception is Officer (forthcoming), where the author produces evidence on acquisition discounts obtained for unlisted targets using the comparable industry transaction method.
} 
unobservable. We observe only completed deals by a given CEO and, therefore, the time between successive completed deals (TBD).

The absence of a proxy for expected profits explains why the results derived in Section 2 are so crucial for establishing empirically testable predictions. Indeed, Proposition 2 provides the necessary foundation for investigating the effects of learning on CAR and TBD.

We begin this third section by establishing the relation between bids, prices and market reactions to deal announcements (CARs). We then derive empirical predictions about CARs and the time between successive deals (TBD.) Finally, we look at how hubris affects these predictions.

\subsection{Investor Information and CAR}

Remember that CAR represents the ex-post observable investors' estimate of the deal value for the shareholders conditionally on doing the deal. This conditional estimate is itself an expectation: the expected value of the target acquisition for the acquirer. As is has been shown that strong-form market efficiency is an unsustainable assumption (see Grossman and Stiglitz (1980)), we rely on the more compelling semi-strong version of market efficiency, wherein investors process all pertinent public information. In such as framework, the acquirer CAR around the announcement date is:

$$
C A R_{A}=\frac{\left(\frac{\mu_{s} M V_{T}}{R}\right)-\left(p\left(\beta\left(v^{*}\right)\right)-M V_{T}\right)}{M V_{A}},
$$

where $M V_{A}$ is the acquirer market value and $1 / R$ is the discount factor. Abnormal returns are the difference between the risk adjusted expected synergy and the premium paid to acquire the target, divided by the acquirer's market value. Under our semi-strong efficiency assumption, investors' synergy anticipation is $\mu_{s}$. This explains why, in Section 1 , market reactions to deal 
announcements were modeled as signals $\tilde{\eta}_{t}$ drawn from $N\left(\mu_{s}, \sigma_{\eta}^{2}\right)$; i.e., market reactions are unbiased. From Proposition 2, bids and ex-post prices are strictly increasing in the CEO's valuation $v^{*}$; consequently, Equation (10) highlights the negative relation between ex-post observed abnormal returns and the CEO's valuation:

$$
\frac{\partial C A R_{A}}{\partial v^{*}}=-\frac{1}{M V_{A}} \frac{\partial p\left(\beta\left(v^{*}\right)\right)}{\partial v^{*}}<0
$$

Equation (11) connects the CEO's valuation to investors' reactions. We are now in position to better understand the observable implications of learning and hubris. Note that this negative relation between ex-post observable CAR and CEO valuation does not conflict with the positive relation between learning and ex-ante equilibrium expected profits of the acquirer. It is the consequence of two phenomena:

- we only capture here one of the two components of expected profits (the wealth effect);

- Equation (10) confirms that the CEO's perception of the risk does not matter to the shareholders, who apply their discount factor $1 / R$ to the expected synergies. The shareholders' discount factor is driven by their diversification opportunities.

\subsection{Empirical Implications of Learning}

As explained in Section 1.2, learning is the process by which the CEO incorporates signals sent by the market at each deal announcement. The Bayesian updating rule progressively forms more precise beliefs about the potential synergies (Equation (3)). Learning has implications for both the pattern of CARs from deal to deal and the probability that the CEO succeeds in making a deal.

The CAR from deal to deal. Using equations (11) and (9), it is now possible to explore the implications of learning on the observed CAR around deal announcements. The logical 
consequences of rational CEO's learning are presented in Figure 3 - Panel A - left chart: the more the CEO learns (receives signals from the market), the more accurate his forecasting ability, and the lower $\hat{\sigma}_{s, t}^{2}$ (see Equation (3)). A decrease in $\hat{\sigma}_{s, t}^{2}$ leads to an increase in the CEO's reservation value (see Equation (9)), which translates (by Proposition 2) into more aggressive bidding behavior and higher acquisition prices. Consequently, the acquirer's CAR (see Equation (11)) declines from deal to deal. This conclusion seems counterintuitive but it is, as explained in introduction of this section, simply a consequence of the reduction in risk perception that learning allows. According to our model, the declining CAR trend reported in introduction is compatible with learning (with the exception of Billet and Qian (2005), who report systematically negative CAR). Therefore, a declining CAR trend from deal to deal does NOT necessarily imply the existence of hubris. Our conclusion is obtained with a constant investment opportunity set (constant $\mu_{s}$ from deal to deal) and thus is not caused by decreasing investment opportunities. Our conclusion is also obtained without any sort of acquirer budget constraint and is therefore not driven by target picking behavior. It is neither a consequence of hubris (or any other form of cognitive bias), since the CEO know the true expected synergy $\mu_{s}$ and is a Bayesian updater. Instead, it is a direct consequence of learning.

\section{Insert Figure 3 About Here}

The probability of doing deals and the TBD. More aggressive bidding affects the probability of a deal. This can be seen for tender offers ${ }^{15}$, as analyzed in Section 2. Recall that the derivation is limited to two rival potential acquirers competing for a given target. Denote by $F_{v_{j}^{*}}\left(. \mid v_{i}^{*}\right)$ the cumulative probability distribution of CEO $j$ 's (the opponent) valuation conditional on CEO $i$ 's

\footnotetext{
${ }^{15}$ A similar argument is valid for the cases of private auction and direct negotiation.
} 
reservation value (the reservation value are positively correlated). Then, the probability that CEO $i$ wins the competition is simply:

$$
\operatorname{Pr}\left(\mathrm{CEO}_{i} \text { valuation }>\mathrm{CEO}_{j} \text { valuation }\right)=F_{v_{j}^{*}}\left(v_{i}^{*} \mid v_{i}^{*}\right)
$$

So, the effect of learning on the probability of winning the competition is:

$$
\frac{d F_{v_{j}^{*}}\left(v_{i}^{*} \mid v_{i}^{*}\right)}{d \hat{\sigma}_{i, t}^{2}}=f_{v_{j}}\left(v_{i}^{*} \mid v_{i}^{*}\right) \frac{d v_{i}^{*}}{d \hat{\sigma}_{i, t}^{2}} \leq 0
$$

On the right side of the equality in Equation (13), the first term is a density function and is therefore non-negative and the second term is negative by Equation (9). Since learning, by Equation (3) reduces $\hat{\sigma}_{i, t}^{2}$, learning leads to an increase in the probability of acquiring the target. This is intuitive: the higher the valuation, the more aggressive the bidding behavior, the higher the probability of outbidding competitors, ceteris paribus. Since the investment opportunity set is constant (the number of acquisition opportunities per time period is constant), learning brings a reduction in the average elapsed TBD (see Figure 3 - Panel A - right chart).

Note that the results of Cantillon (forthcoming) show that the positive effect of learning (asymmetry) on the probability of acquiring the target (the probability of winning the auction) dominates the negative effects of learning on CAR (the wealth effect conditional on doing the deal) in equilibrium.

\subsection{On the Implications of Hubris}

How does hubris affect the empirical implications of learning? To explore such an issue, we must first define precisely what hubris means. Following Malmendier and Tate (2006), hubris is a cognitive bias in the CEO's decision making process. Hubris can affect either the CEO's initial perception (the anticipated synergy at the first deal attempt), or his learning process (the 
interpretation of market reactions to past deals), or both. For simplicity, we now assume that hubris affects the CEO's initial perception. ${ }^{16}$ If he is not fired after completing his first acquisition, we assume he will learn something, despite the initial hubris. From deal to deal, this learning process should bring a progressive correction of the initial bias. Perhaps this assumption does not describe the behavior of every CEOs seemingly infected by hubris. Well-known instances reported in the financial press do allow for much optimism... but it seems reasonable to presume that CEOs unable to overcome hubris will be fired at a higher rate than others who correct erroneous initial assessments. Learning CEOs should therefore have a higher survival rate. $^{17}$

A CEO's initial perception may be biased in two dimensions: with respect to expected synergies or with respect to the perceived volatility of synergies. Hubris can be characterized as over-optimism $\left(\hat{\mu}_{0, s}>\mu_{s}\right)$ or as over-confidence $\left(\hat{\sigma}_{0, t}^{2}<\sigma_{0, t}^{2}\right)$. Since either cognitive biases leads to the same empirical predications, we analyze only the first case and define a hubrisinfected CEOs as having the prior $N\left(\hat{\mu}_{0, s}, \hat{\sigma}_{s, 0}^{2}\right)$, with $\hat{\mu}_{0, s}>\mu_{s}$. The immediate consequence is that Equation (2) no longer holds:

$$
\hat{\mu}_{s, t}=\frac{\left(\frac{1}{\hat{\sigma}_{s, 0}^{2}} \hat{\mu}_{0, s}+\frac{1}{\sigma_{\eta}^{2}} \sum_{i=1}^{t-1} \eta_{i}\right)}{\frac{1}{\hat{\sigma}_{s, 0}^{2}}+(t-1) \frac{1}{\sigma_{\eta}^{2}}}>\mu_{s} .
$$

\footnotetext{
${ }^{16}$ Analyzing the empirical consequences of growing hubris from deal to deal could be a promising future research avenue, perhaps pertinent to large and active serial acquirers headed by notoriously overconfident CEOs.

${ }^{17}$ This raises a question of why, in the long run, any CEOs at all remain hubris infected. Perhaps an endogenous treatment of corporate governance mechanisms would provide the key to an answer, an interesting issue for future research.
} 
But, if signals send by the market are informative:

$$
\lim _{t \rightarrow \infty} \hat{\mu}_{s, t}=\frac{\left(\frac{1}{\hat{\sigma}_{s, 0}^{2}} \hat{\mu}_{0, s}+\frac{1}{\sigma_{\eta}^{2}} \sum_{i=1}^{t-1} \eta_{i}\right)}{\frac{1}{\hat{\sigma}_{s, 0}^{2}}+(t-1) \frac{1}{\sigma_{\eta}^{2}}}=\mu_{s}
$$

The CEO's perception of expected synergies converges towards the true population value: learning progressively corrects the initial distorted perception.

Before exploring the empirical predictions of hubris, we should mention that the cognitive bias does not by itself violate the Harsanyi coherence doctrine. So long as the CEO's beliefs remain internally consistent, the Bayesian Nash equilibrium solution concept used in Section 2 remains well defined.

As hubris infected CEOs (or equivalently over-optimistic CEOs in our setup) over-value the target; using the implications of Proposition 2, they overbid. Following the same reasoning as in Section 3.2, they over-pay for the target. One should therefore observe either an initial negative CAR or a surprisingly low initial CAR (with respect to the true potential synergies). ${ }^{18}$ With subsequent learning, the same CEOs should progressively correct their initial perceptions, improve their valuation abilities, bid more cautiously, and reduce any value destruction. But, as they bid less aggressively, they should win less frequently in competition with other acquirers. These predictions are summarized in Figure $4-$ Panel B and C. ${ }^{19}$ In the case of a negative initial CAR (Panel B), the source of learning is the negative investor reaction at the first deal's

\footnotetext{
${ }^{18}$ Overbidding will not necessarily result in a negative CAR if synergies are high enough. The hubrisinfected CEO bid could concede too high a fraction of the wealth created to target shareholders but still retain some wealth for acquiring shareholders.

${ }^{19}$ As explained in Section 1.7 (see equations (8) and (8')), we must remain careful at this point of the analysis. For already highly remunerated CEOs, risk-aversion could lead to the opposite behavior.
} 
announcement. In the case of a low initial CAR (relative to the true synergies), the source of the learning could be the action of a well-informed shareholder (who is aware of the CEO's overbidding behavior) or the CEO's reaction to a disappointingly low CAR.

These implications contrast sharply with the literature's previous contention that hubrisinfected CEO's should experience a declining CAR from deal to deal. If hubris-infected CEOs also learn (an assumption difficult to dismiss out of hand, particularly given internal and external corporate governance mechanisms), the observed CAR trend should actually be growing (in the case of Panel $\mathrm{C}$, at least relative to the CAR that would have been observed with rational CEOs.) The decreasing rhythm (i.e., growing TBD) for hubris-infected CEOs is indirectly pointed out in Conn et al. (2004).

Sections 3.2 and 3.3 imply our third and final proposition.

PROPOSITION 3. Empirical implications of learning and hubris

Under the assumptions of Proposition 1 and Proposition 2, assuming semi-strong form market efficiency, the CAR and TBD trends of acquisition programs undertaken by rational CEOs should be decreasing (see Figure 3 - Panel A). For hubris infected CEOs, (whose cognitive biases are assumed to affect their prior perceptions of expected synergies), the CAR and TBD trends of acquisition programs should be increasing (see Figure 3 - Panels B and C).

Note finally that the predictions of Proposition 3 on both the CAR and the TBD, for rational and hubris infected CEOs, are specific to our learning framework. In particular, decreasing investment opportunities could explain a declining CAR, but it would be common to both types of CEOs.

\section{Conclusion ${ }^{20}$}

\footnotetext{
${ }^{20}$ We provide additional material about empirical issues in the On-Line Appendix to this paper.
} 
The declining trend of CARs in acquisition programs is an empirical fact. The theory presented here suggests that the pattern is not necessarily due to CEOs infected by hubris. Economically motivated risk averse rational CEOs who learn from investor reactions to past deal announcements, should adopt a behavior that leads to the observed empirical pattern. However, the declining CAR trend could be due to other causes, such as a declining investment opportunity set, budget constraints or increasing competition during merger waves.

But our learning hypothesis delivers specific and unique predictions that can serve as the bases for distinguishing empirical tests. These predictions are about both the announcement period cumulative abnormal return of acquiring firms (the CAR) and about the time between successive acquisitions, (TBD), for both rational and hubris infected CEOs. In short, rational CEOs, learning form deal to deal, should bid more aggressively over time. The fraction of synergies they concede to target shareholders should increase over time, leading to a declining CAR, and more frequent success in beating competitors, hence reducing also the TBD). The reverse should hold for hubris-infected CEOs. The mechanism at play is reminiscencent of the Milgrom and Weber (1982) analysis of information disclosure with risk averse bidders.

Note also that, as the CEO is more risk averse than his shareholders, his bidding behavior is suboptimal from the point of view of the shareholders. This can be interpreted as a sort of agency cost. We show in Section 1 that learning reduces the CEO's perception of risks associated with the target acquisition. So, learning reduces the gap between the bidding behavior adopted by the CEO and the one desired by shareholders.

Our conclusions are obtained within a private valuation framework where synergies are assessed without considering potential competing bidders. Extending the analysis to a common value framework might bring additional insights. In common-value auctions, bidders' valuations 
depend on the valuations of competitors, which are revealed by their bidding behavior. Modeling such a situation is complex but perhaps worthwhile. 


\section{References}

Arozamena, Leandro, Cantillon, Estelle, 2004, Investment Incentives in Procurement Auctions, Review of Economic Studies 71, 1-18

Ahern, Kenneth R., 2006, Markets talk, firms listen: The dynamics of repeat acquirers, UCLA Working Paper.

Andrade, George, Mark Mitchell, and Erik Stafford, 2001, New evidence and perspectives on mergers, Journal of Economic Perspectives 15, 103-120.

Barro, Robert J., 2006, Rare disasters and asset markets in the twentieth century, Quarterly Journal of Economics 121, 823-866.

Becker, Bo, 2006, Wealth and executive compensation, Journal of Finance 61, 379-397.

Bertrand, Marianne, and Antoinette Schoar, 2003, Managing with style: the effect of managers on firm policies, Quarterly Journal of Economics 118, 1169-1208.

Betton, Sandra, Espen B. Eckbo, and Karin S. Thorburn, 2005, The toehold puzzle, Tuck School of Business Working Paper No. 2005-16, http://ssrn.com/abstract=715601.

Billett, Matthew T., and Yiming Qian, 2005, Are overconfident managers born or made? Evidence of self-attribution bias from frequent acquirers, AFA 2006 Boston Meetings Paper, http://ssrn.com/abstract=687534.

Boone, Andra L., and Harold J. Mulherin, 2007, How are firms sold?, Journal of Finance 62, 847-875.

Bulow, Jeremy I., Ming Huang, and Paul D. Klemperer, 1999, Toeholds and takeovers, Journal of Political Economy 107, 427-454

Cai, Jie, and Anand M. Vijh, 2006, Incentive Effects of Stock and Options Holdings of Target and Acquirer CEOs, forthcoming Journal of Finance.

Cantillon, Estelle, 2006, The Effect of Bidders' Asymmetries on Expected Revenues in Auctions, forthcoming Games and Economic Behavior

Conn, Robert L., Andy Cosh, Paul M. Guest, and Alan Hugues, 2005, Why must all good things come to an end? The performance of multiple acquirers, Working paper, University of Cambridge, http://ssrn.com/abstract $=499310$.

Croci, Ettore, 2005, Why do managers make serial acquisitions? An investigation of performance predictability in serial acquisitions, http://ssrn.com/abstract=727503.

Datta, Sudip, Mai Iskandar-Datta, and Kartik Raman, 2001, Executive compensation and corporate acquisition decisions, Journal of Finance 56, 2299-2336. 
Fuller, Kathleen, Jeffry Netter, and Michael A. Stegemoller, 2002, What do returns to acquiring firms tell us? Evidence from firms that make many acquisitions, Journal of Finance 57, 17631793.

Grinstein, Yaniv, and Paul Hribar, 2004, CEO compensation and incentives: Evidence from M\&A Bonuses, Journal of Financial Economics 73, 119-143.

Grossman, Sanford J., and Joseph E. Stiglitz, 1980, On the impossibility of informationally efficient markets, American Economic Review 70, 393-408.

Hall, Brian J., and Jeffrey B. Liebman, 1998, Are CEOs Really Paid Like Bureaucrats?, Quarterly Journal of Economics 113,653-691.

Hall, Brian J., and Kevin J. Murphy, 2002, Stock options for undiversified executives, Journal of Accounting and Economics 33, 3-42.

Hansen, Robert G., 2001, Auctions of companies, Economic Inquiry 39, 30-43.

Harding, David, and Sam Rovit, 2004, Building deals on bedrock, Harvard Business Review 82, 121-128.

Harford, Jarrad, 2005, What drives merger waves, Journal of Financial Economics 77, 529-560.

Hayward, Mathem L.A. 2002, When do firms learn from their acquisition experience?, Evidence from 1990-1995, Strategic Management Journal 23, 21-39.

Ismail, Ahmad, 2006, Will multiple acquirers ever learn? The US evidence from single versus multiple acquirers, http://ssrn.com/abstract=765245.

Jensen, Michael C., 1986, Agency costs of free cash flow, corporate finance, and takeovers, American Economic Review 76, 323-329.

Jensen, Michael C., and Richard S. Ruback, 1983, The market for corporate control: The scientific evidence, Journal of Financial Economics 11, 5-50.

Klasa, Sandy, and Michael A. Stegemoller, Takeover activity as a response to time-varying changes in investment opportunity sets: Evidence from takeover sequences, forthcoming Financial Management.

Lehn, Kenneth and Mengxin Zhao, 2006, CEO turnover after acquisitions: Do bad bidders get fired?, Journal of Finance 61, 1759-1811.

Malatesta, Paul H., and Rex Thompson, 1985, Partially anticipated events: A model of stock price reactions with an application to corporate acquisitions, Journal of Financial Economics 14, 237-250.

Malmendier, Ulrike, and Geoffrey A. Tate, 2006, Who makes acquisitions? CEO overconfidence and the market's reaction, Working paper, NBER No. 10813. 
Maskin, Eric, and Johan Riley, 2000, Asymmetric auctions, Review of Economic Studies 67, 413438.

Milgrom, Paul R., 2004, Putting auction theory to work, Cambridge University Press.

Milgrom, Paul R., and Robert J. Weber, 1982, A theory of auctions and competitive bidding, Econometrica 50, 1089-1122.

Mitchell, Mark L., and Kenneth Lehn, 1990, Do bad bidders become good targets, Journal of Political Economy 98, 372-398.

Mitchell, Marl L., and Harold J. Mulherin, 1996. The impact of industry shocks on takeover and restructuring activity. Journal of Financial Economics 41, 193-229.

Moeller, Sara B., Frederik P. Schlingemann, and René M. Stulz, 2004, Firm size and the gains from acquisitions, Journal of Financial Economics 73, 201-228

Officer, Micah S., The price of corporate liquidity: Acquisition discounts for unlisted targets, forthcoming Journal of Financial Economics.

Povel, Paul and Singh, Rajdeep, 2006, Takeover contests with asymmetric bidders, Review of Financial Studies 19, 1399-1431.

Roll, Richard, 1986, The hubris hypothesis of corporate takeovers, Journal of Business 59, 197 216.

Rovit, Sam, David Harding, and Catherine Lemire, 2003, Turning deal smarts into M\&A payoffs: Frequent buyers usually score the best deals, provided that they add skills in each transaction, Merger and Acquisitions: The Dealmakers Journal (09/01/03).

Schipper, Katherine, and Rex Thompson, 1983, Evidence on the capitalized value of merger activity for acquiring firms, Journal of Financial Economics 11, 85-120.

Schwert, W., 2000, Hostility in takeovers: In the eye of beholder?, Journal of Finance 55, 25992640.

Shleifer, Andrei, and Robert W. Vishny, 2003, Stock market driven acquisitions, Journal of Financial Economics 70, 295-311. 


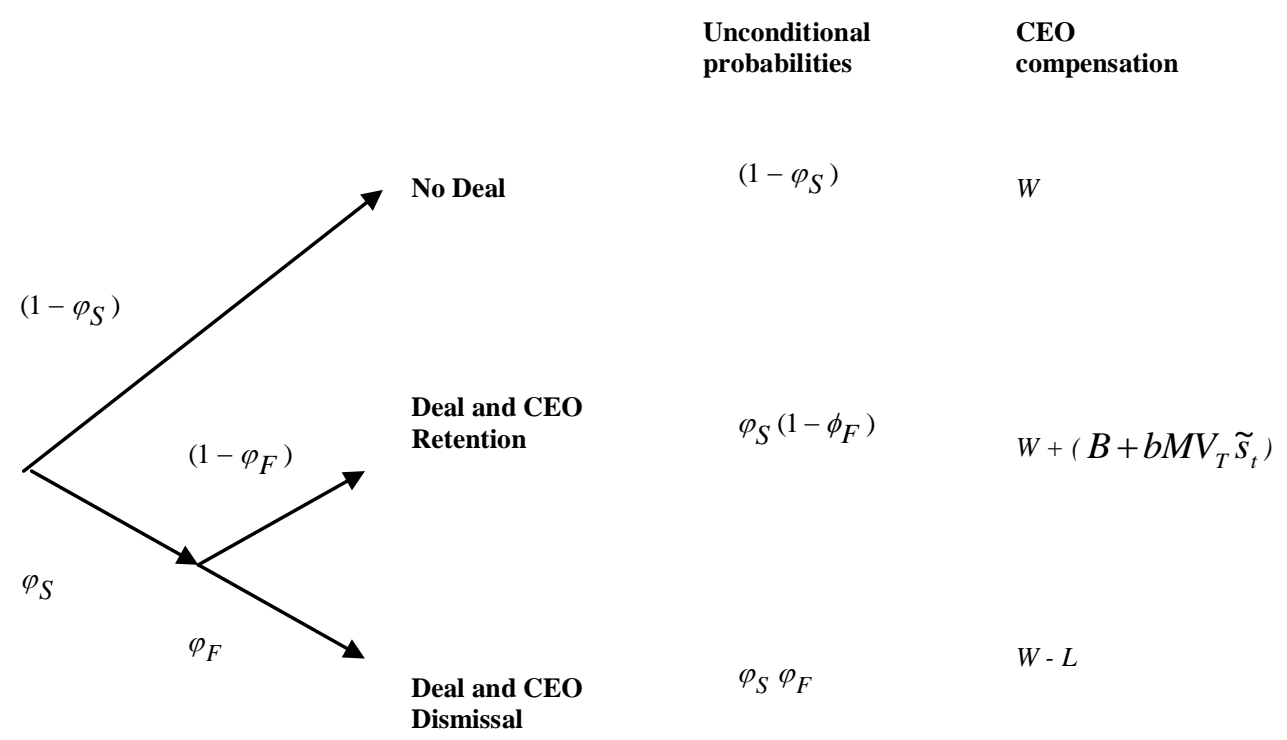

Figure 1. The CEO's decision problem. $\varphi_{S}$ denotes the probability of a successful deal and $\varphi_{F}$ the probability of being dismissed after disappointing ex-post realized synergies with respect to the acquisition price, conditionally on having done the deal. $W, B+b M V_{T} \widetilde{s}_{t}$, and $L$ denote, respectively, the present value of the CEO's current compensation, his bonus after deal completion and his loss from being dismissed. 


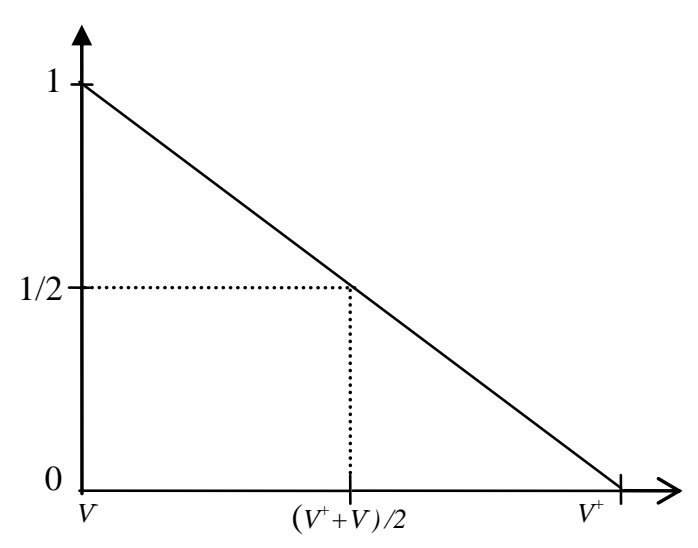

$v$

Panel A. No Deal

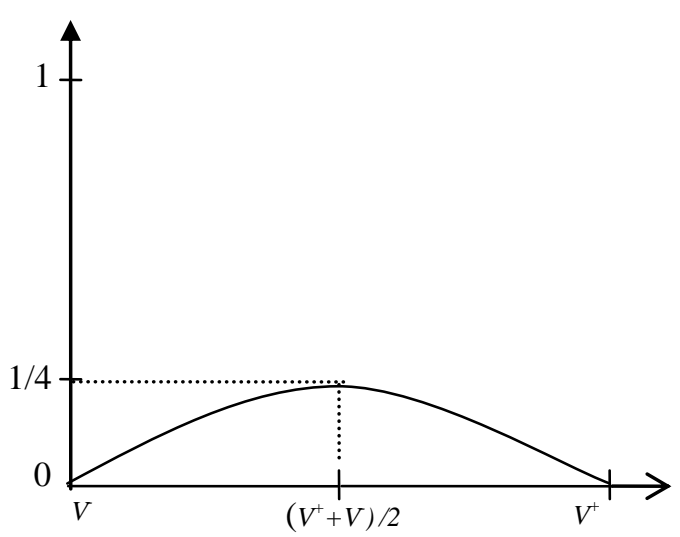

$v$

Panel B. Deal and CEO Retention

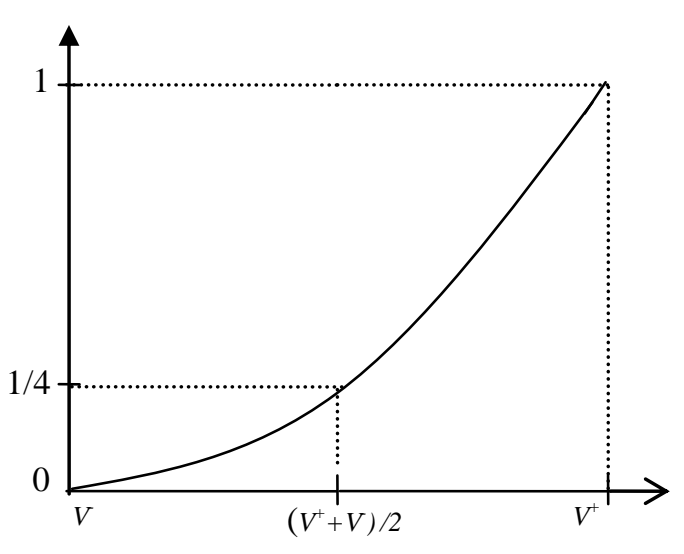

$v$

Panel C. Deal and CEO Dismissal

Figure 2. Unconditional probabilities as functions of target valuation $v$. Panel A plots the probability of missing out on the deal, which decreases linearly as $v$ increases. Panel B shows the probability doing the deal and not being fired. Panel C plots the probability of being fired, given that the CEO has completed the acquisition. The $\mathrm{y}$-axis gives the probability, and the $\mathrm{x}$-axis gives the level of $v$. 

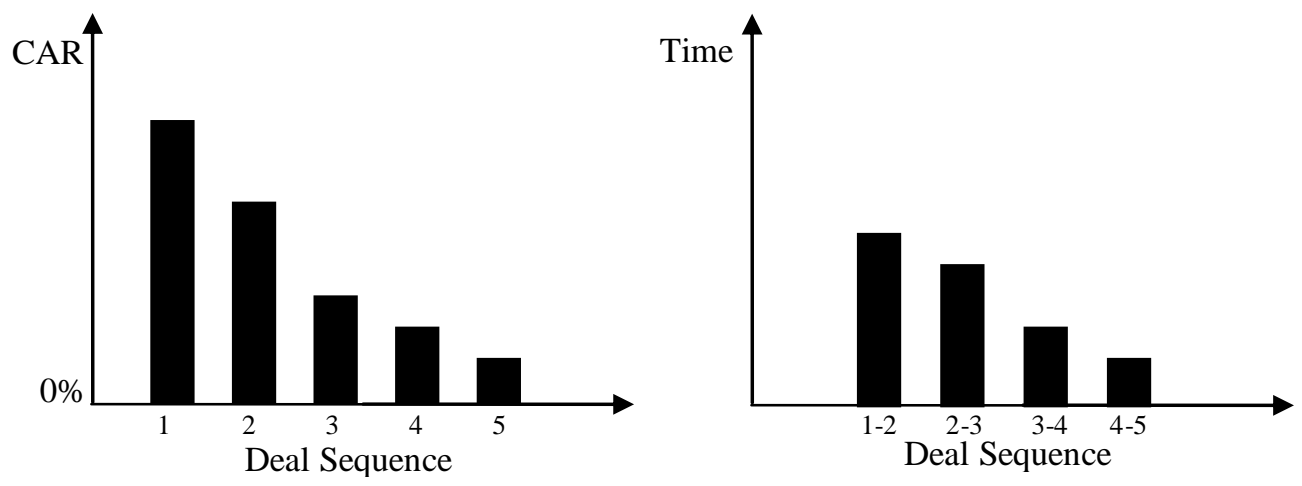

Panel A. Rational CEOs
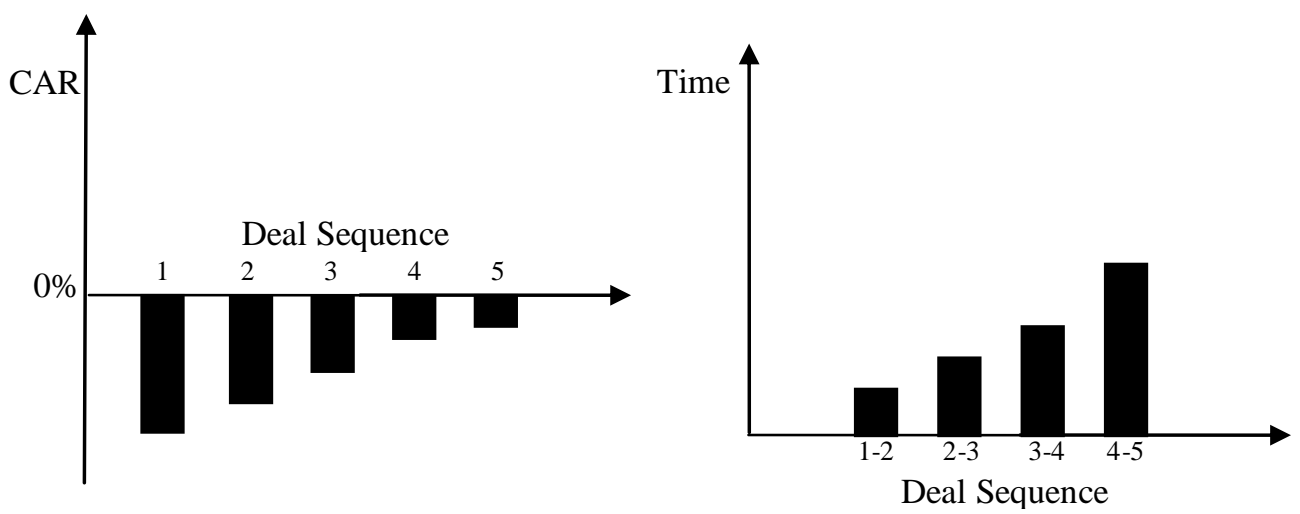

Panel B. Hubris infected CEOs - initial negative CAR
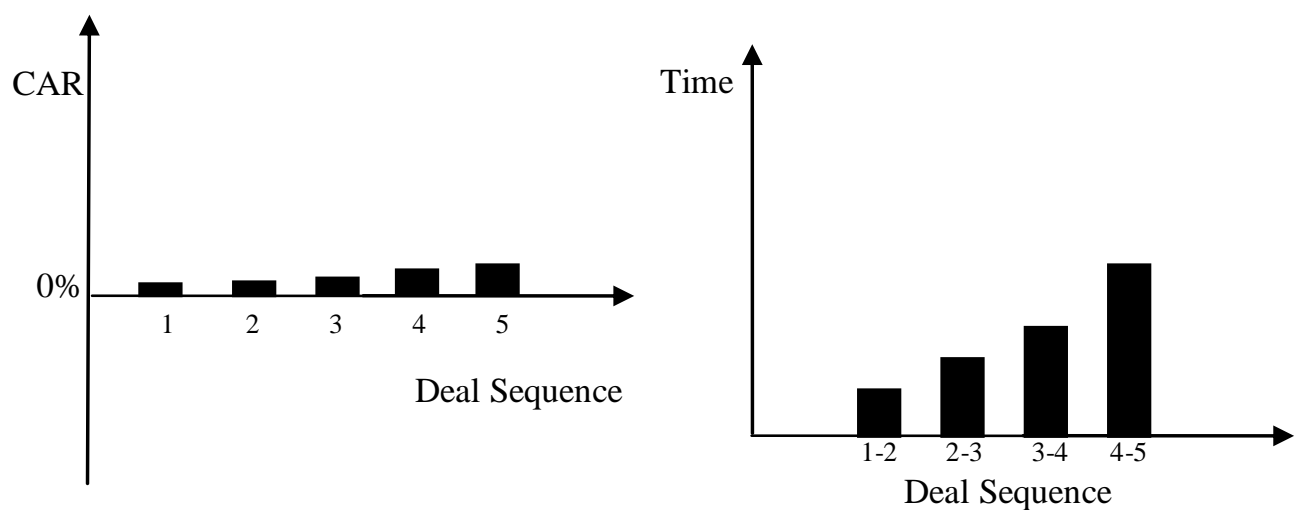

Panel C. Hubris infected CEOs - initial disappointing CAR

Figure 3. Bidder cumulative abnormal returns (CAR) and time between successive deals (TBD). The $\mathrm{X}$-axis represents the deal sequence order number in an acquisition program undertaken by the same CEO. The Y-axis is either the ex-post observable CAR or the TBD. Panel A - left chart, considering rational CEOs, shows the declining pattern of ex-post observable CARs from deal to deal, as a consequence of the learning process. The associated right chart highlights the shortening TBD. Panel $\mathrm{B}$, focusing on hubris infected CEOs, illustrates the opposite pattern. Panel $\mathrm{C}$ summarizes predictions for hubris-infected CEOs when investors' reactions are positive but disappointing. 


\section{List of supplements}

Supplement A - Evidence from the Literature on Bidders' CAR Patterns across Deals

Supplement B - Notations and Conventions

Supplement C - Market Value of the Target in Case of Acquisition: An Alternative Specification

Supplement D - Equation 6 derivation

Supplement E - Common upper bound of probabilities of success and of being dismissed

Supplement F - Proposition 1 derivation

Supplement G - Positive risk adjusted bonus

Supplement $\mathbf{H}$ - Determinants of the CEO valuation

Supplement I - Proposition 2 derivation

Supplement J - Empirical issues 


\section{Supplement A - Evidence from the Literature on Bidders' CAR Patterns across Deals}

This table displays average bidders' cumulative abnormal returns (CAR) during acquisition programs. $N$ is the total number of acquisitions in the sample.

\begin{tabular}{|c|c|c|c|c|c|c|c|}
\hline & Sample features & \multicolumn{6}{|c|}{ Deal sequence } \\
\hline $\begin{array}{r}\text { Fuller et al. (2002) } \\
\text { 5-day Market-Adjusted } \\
\text { CAR }\end{array}$ & $\begin{array}{c}\text { Period: } 1990-2000 \\
N=3,135 \\
\text { U.S. bidders }\end{array}$ & & $\begin{array}{c}\mathbf{1}^{\text {st }} \\
2.74 \%\end{array}$ & & & $\begin{array}{c}5^{\text {th }} \text { and }> \\
0.52 \%\end{array}$ & \\
\hline $\begin{array}{r}\text { Billett and Qian (2005) } \\
\text { 5-day Market Model } \\
\text { CAR }\end{array}$ & $\begin{array}{c}\text { Period: } 1985-2002 \\
N=3,702 \\
\text { U.S. bidders and } \\
\text { listed U.S. targets }\end{array}$ & $\begin{array}{c}\mathbf{1}^{\mathbf{s t}} \\
-0.10 \%\end{array}$ & $\begin{array}{c}\mathbf{2}^{\text {nd }} \\
-1.54 \%\end{array}$ & $\begin{array}{c}\mathbf{3}^{\text {rd }} \\
-1.37 \%\end{array}$ & $\begin{array}{c}\mathbf{4}^{\text {th }} \\
-1.66 \%\end{array}$ & $\begin{array}{c}\mathbf{5}^{\mathbf{t h}} \\
-1.21 \%\end{array}$ & $\begin{array}{c}\mathbf{6}^{\mathbf{t h}} \\
-1.74 \%\end{array}$ \\
\hline $\begin{array}{r}\text { Croci (2005) } \\
\text { 5-day Market Model } \\
\text { CAR }\end{array}$ & $\begin{array}{c}\text { Period: } 1990-2002 \\
N=4,285 \\
\text { U.S. bidders }\end{array}$ & $\begin{array}{c}\mathbf{1}^{\mathbf{s t}} \\
1.60 \%\end{array}$ & $\begin{array}{c}\mathbf{2}^{\text {nd }} \\
1.62 \%\end{array}$ & $\begin{array}{c}\mathbf{3}^{\text {rd }} \\
1.13 \%\end{array}$ & $\begin{array}{c}\mathbf{4}^{\text {th }} \\
1.00 \%\end{array}$ & $\begin{array}{c}\mathbf{5}^{\text {th }} \\
1.12 \%\end{array}$ & $\begin{array}{c}>\mathbf{5} \\
-0.41 \%\end{array}$ \\
\hline $\begin{array}{r}\text { Conn et al. (2005) } \\
\text { 3-day Market-Adjusted } \\
\text { CAR }\end{array}$ & $\begin{array}{c}\text { Period: } 1984-1998 ; \\
N=3,842 \\
\text { U.K. bidders }\end{array}$ & $\begin{array}{c}\mathbf{1}^{\text {st }} \\
0.88 \%\end{array}$ & $\begin{array}{l}\mathbf{2}^{\text {nd }} \\
0.4\end{array}$ & & & $\begin{array}{c}>\mathbf{3} \\
-0.16 \%\end{array}$ & \\
\hline $\begin{array}{r}\text { Ismail (2006) } \\
\text { 5-day Market Model } \\
\text { CAR }\end{array}$ & $\begin{array}{c}\text { Period: } 1985-2004 \\
N=16,221 \\
\text { U.S. bidders }\end{array}$ & $\begin{array}{c}\mathbf{1}^{\text {st }} \\
1.41 \%\end{array}$ & $\begin{array}{c}\mathbf{2}^{\text {nd }} \\
1.52 \%\end{array}$ & $\begin{array}{c}\mathbf{3}^{\text {rd }} \\
1.44 \%\end{array}$ & $\begin{array}{c}\mathbf{4}^{\text {th }} \\
0.81 \%\end{array}$ & $\begin{array}{c}\mathbf{5}^{\text {th }} \\
0.22 \%\end{array}$ & $\begin{array}{c}\mathbf{6}^{\text {th }} \\
0.32 \%\end{array}$ \\
\hline $\begin{array}{l}\text { Ahern (2006) } \\
\text { 5-day Market-Adjusted } \\
\text { CAR }\end{array}$ & $\begin{array}{c}\text { Period: } 1981-2004 \\
N=12,942 \\
\text { U.S. bidders }\end{array}$ & $\begin{array}{c}\mathbf{1}^{\mathbf{s t}} \\
3.19 \%\end{array}$ & $\begin{array}{c}\mathbf{2}^{\text {nd }} \\
2.10 \%\end{array}$ & $\begin{array}{c}\mathbf{3}^{\text {rd }} \\
1.53 \%\end{array}$ & $\begin{array}{c}\mathbf{4}^{\text {th }} \\
1.52 \%\end{array}$ & $\begin{array}{c}\mathbf{5}^{\text {th }} \\
0.84 \%\end{array}$ & $\begin{array}{c}>\mathbf{5} \\
-0.11 \%\end{array}$ \\
\hline
\end{tabular}

Ahern, Kenneth R., 2006, Markets talk, firms listen: The dynamics of repeat acquirers, UCLA Working Paper.

Billett, Matthew T., and Yiming Qian, 2005, Are overconfident managers born or made? Evidence of self-attribution bias from frequent acquirers, AFA 2006 Boston Meetings Paper, http://ssrn.com/abstract=687534.

Conn, Robert L., Andy Cosh, Paul M. Guest, and Alan Hugues, 2005, Why must all good things come to an end? The performance of multiple acquirers, Working paper, University of Cambridge, http://ssrn.com/abstract=499310.

Croci, Ettore, 2005, Why do managers make serial acquisitions? An investigation of performance predictability in serial acquisitions, http://ssrn.com/abstract $=727503$.

Fuller, Kathleen, Jeffry Netter, and Michael A. Stegemoller, 2002, What do returns to acquiring firms tell us? Evidence from firms that make many acquisitions, Journal of Finance 57, 17631793.

Ismail, Ahmad, 2006, Will multiple acquirers ever learn? The US evidence from single versus multiple acquirers, http://ssrn.com/abstract=765245. 


\section{Supplement B - Notations and Conventions}

\begin{tabular}{|c|c|}
\hline$\sim$ & Indicates a random variable \\
\hline$\wedge$ & Indicates a perceived value of a population parameter \\
\hline$\mu_{s}$ & Population (or real) value of expected synergies \\
\hline$\hat{\mu}_{s, t}$ & Expected synergies at deal $t$ as perceived by the CEO \\
\hline$M V_{T}$ & Target market value \\
\hline$\tilde{s}_{t}$ & Synergies created by the merger \\
\hline$\sigma_{s}^{2}$ & Population (or real) value of the variance of synergies \\
\hline$\hat{\sigma}_{s, t}^{2}$ & Variance of the synergies at deal $t$ as perceived by the CEO \\
\hline$\tilde{\eta}_{t}^{s, t}$ & Signal sent by the market at deal $t$ announcement about potential synergies \\
\hline$\sigma_{\eta}^{2}$ & Variance of the signals sent by the market (market informativeness) \\
\hline$\varphi_{S}$ & Probability of successful deal \\
\hline$\varphi_{F}$ & Probability of CEO being firing due to disappointing synergies ex post \\
\hline$v$ & CEO valuation of the target \\
\hline$p()$. & Price function \\
\hline$\beta()$. & Bidding function \\
\hline$W$ & Present value of the CEO's current wage contract \\
\hline$L$ & Penalty incurred by the CEO from being dismissed \\
\hline$B+b \tilde{s}_{t}$ & $\begin{array}{l}\text { CEO bonus associated with a successful deal ( } B \text { is the fixed part and } b \text { is the } \\
\text { variable part) }\end{array}$ \\
\hline$U()$. & CEO Utility function \\
\hline$\gamma$ & CEO risk aversion \\
\hline$V^{-}$ & Minimum valuation of the target to have any chance of a successful deal \\
\hline$V_{S}^{+}=\beta^{-1}\left(p^{-1}\left(\theta M V_{T}\right)\right)$ & $\begin{array}{l}\text { Target valuation, defined as some multiple } \theta \text { of the current market value, such } \\
\text { that the induced bid guarantees that the deal attempt will succeed with } \\
\text { probability one }\end{array}$ \\
\hline$V_{F}^{+}=\beta^{-1}\left(p^{-1}\left(\theta M V_{T}\right)\right)$ & $\begin{array}{l}\text { Target valuation, defined as some multiple } \theta \text { of the current market value, such } \\
\text { that the induced price would be so high that ex-post synergies would be highly } \\
\text { disappointing and would lead, with probability one, to the CEO being fired. }\end{array}$ \\
\hline$F_{v_{j}^{*}}\left(. \mid v_{i}^{*}\right)$ & $\begin{array}{l}\text { The distribution of CEO } j \text { reservation values conditional on CEO } i \text { reservation } \\
\text { values }\end{array}$ \\
\hline$f_{v, *}\left(. \mid v_{i}^{*}\right)$ & Corresponding density function. \\
\hline$\pi_{i}\left(b, v_{i}^{*}\right)$ & CEO $i$ expected surplus when he has valuation $v_{i}^{*}$ and bids $b$. \\
\hline
\end{tabular}




\section{Supplement C- Market Value of the Target in Case of Acquisition: An Alternative Specification}

As in Section 1, the synergy potentially created by the merger is not perfectly known to the acquirer. We denote it $\tilde{s}_{t}$. We however specify this time the target market value $\left(M V_{T}\right)$ in case of deal completion as:

$$
M V_{T} \mid \text { acquisition }=M V_{T} \times e^{\tilde{s}_{t}}
$$

instead of Equation (1). This modification sets the lower bound on the target market value to zero in case of acquisition. We still assume that $\tilde{s}_{t}$ follows a Gaussian distribution $N\left(\mu_{s}, \sigma_{s}^{2}\right)$.

In this modified setup, the CEO's bonus follows a log-normal distribution with first and second moments given by:

$$
E\left(B+b M V_{T}\left(e^{\tilde{s}_{t}}-1\right)\right)=B+b M V_{T}\left[e^{\mu_{s}+\frac{1}{2} \hat{\sigma}_{s, t}^{2}}-1\right]
$$

(instead of $B+b \mu_{s}$ in the Section 1 setup).

$$
\begin{aligned}
& E\left(\left(B+b M V_{T}\left(e^{\tilde{s}_{t}}-1\right)\right)^{2}\right)=B^{2}+b^{2} M V_{T}^{2}\left[e^{2 \mu_{s}+2 \hat{\sigma}_{s, t}^{2}}-2 e^{\mu_{s}+\frac{1}{2} \hat{\sigma}_{s, t}^{2}}+1\right] \\
& +2 b M V_{T}\left[e^{\mu_{s}+\frac{1}{2} \hat{\sigma}_{s, t}^{2}}-1\right]
\end{aligned}
$$

(instead of $b^{2} M V_{T}^{2} \hat{\sigma}_{s, t}^{2}+\left(B+b M V_{T} \mu_{s}\right)$ in the Section 1 setup).

By doing the necessary adjustments to Section 1.6, the CEO's valuation of the target becomes:

$$
\frac{v^{*}-V^{-}}{V^{+}-V^{-}}=\frac{1}{2} \frac{B+b M V_{T}\left[e^{\mu_{s}+\frac{1}{2} \hat{\sigma}_{s, t}^{2}}-1\right]-\gamma / 2\left[B^{2}+b^{2} M V_{T}^{2}\left[e^{2 \mu_{s}+2 \hat{\sigma}_{s, t}^{2}}-2 e^{\mu_{s}+\frac{1}{2} \hat{\sigma}_{s, t}^{2}}+1\right]+2 b M V_{T}\left[e^{\mu_{s}+\frac{1}{2} \hat{\sigma}_{s, t}^{2}}-1\right]\right]}{\left(B+b M V_{T}\left[e^{\mu_{s}+\frac{1}{2} \hat{\sigma}_{s, t}^{2}}-1\right]-\gamma / 2\left[B^{2}+b^{2} M V_{T}^{2}\left[e^{2 \mu_{s}+2 \hat{\sigma}_{s, t}^{2}}-2 e^{\mu_{s}+\frac{1}{2} \hat{\sigma}_{s, t}^{2}}+1\right]+2 b M V_{T}\left[e^{\mu_{s}+\frac{1}{2} \hat{\sigma}_{s, t}^{2}}-1\right]\right]\right)+\left(L+\gamma / 2 L^{2}\right)}
$$

So, using the Equation (C1) specification and properties of the log-normal distribution, we can still derive the CEO's reservation value. Equation (C4) can be used to explore, as in Section 
1.7, the determinants of the CEO's valuation. For example, it can be shown that a sufficient condition for the CEO's valuation to decline with perceived synergies is that the risk aversion coefficient $\gamma$ be bigger than 2 .

To sum-up, it is technically possible to adopt a specification such that the lower bound of the target market value in case of acquisition is zero. But this complicates the exposition without providing more insights. 


\section{Supplement D - Equation 6 derivation}

The expected utility of the CEO is given by:

$$
E(U)=\left(1-\varphi_{S}\right) U(W)+\varphi_{S}\left(1-\varphi_{F}\right) E\left(U\left(W+B+b M V_{T} \tilde{s}_{t}\right)\right)+\varphi_{S} \varphi_{F} U(W-L),
$$

where $U($.$) denotes the CEO utility function. We approximate it by a second-order Taylor series$ expansion around $W$. This leads to the following expressions:

$$
\begin{gathered}
U(W-L)=U(W)-L U^{\prime}(W)+\frac{1}{2} L^{2} U^{\prime \prime}(W) . \\
U\left(W+B+b M V_{T} \tilde{s}_{t}\right)=U(W)+\left(B+b M V_{T} \tilde{s}_{t}\right) U^{\prime}(W)+\frac{1}{2}\left(B+b M V_{T} \tilde{s}_{t}\right)^{2} U^{\prime \prime}(W) .
\end{gathered}
$$

Substituting Equations (6) and (7) into Equation (5) yields:

$$
E(U)=U(W)+\varphi_{S}\left[\begin{array}{l}
{\left[\left(1-\varphi_{F}\right)\left(B+b M V_{T} \mu_{s}\right)-\varphi_{F} L\right] U^{\prime}(W)} \\
\left.+\left[\varphi_{F} \frac{L^{2}}{2}+\left(1-\varphi_{F}\right) \frac{\left(b^{2} M V_{T}^{2} \hat{\sigma}_{s, t}^{2}+\left(B+b M V_{T} \mu_{s}\right)^{2}\right)}{2}\right] U^{\prime \prime}(W)\right]
\end{array}\right.
$$

The CEO chooses $v$, the target valuation, in order to maximize his expected utility. This leads to the following first order condition:

$$
\begin{aligned}
& {\left[\varphi_{S}^{\prime}-\left(\varphi_{S} \varphi_{F}\right)^{\prime}\right]\left(B+b M V_{T} \mu_{S}\right)-\left(\varphi_{S} \varphi_{F}\right)^{\prime} L} \\
& -\gamma\left[\left(\varphi_{S}^{\prime}-\left(\varphi_{S} \varphi_{F}\right)^{\prime}\right) \frac{\left(b^{2} M V_{T}^{2} \hat{\sigma}_{s, t}^{2}+\left(B+b M V_{T} \mu_{s}\right)^{2}\right)}{2}+\left(\varphi_{S} \varphi_{F}\right)^{\prime} \frac{L^{2}}{2}\right]=0
\end{aligned}
$$

where $\gamma$ is the absolute risk aversion coefficient $-U^{\prime \prime}(W) / U^{\prime}(W)$. 


\section{Supplement E - Common upper bound of probabilities of success and of being dismissed}

Ex-ante, $\varphi_{S}$ and $\varphi_{F}$ must have common range. As explained in Section 1.5, they have the same lower bound $V^{-}$. Suppose that $V_{F}^{+}>V_{S}^{+}$, for any valuation between $V_{F}^{+}$and $V_{S}^{+}$, the deal would succeed with probability one and the probability of being fired would continue to increase. Hence, there would be no reason for the CEO to value the target above $V_{S}^{+}$. The same kind of argument applies for the case $V_{F}^{+}<V_{S}^{+}$. So, we assume, without loss of generality, that $V_{F}^{+}=V_{S}^{+}: \varphi_{S}$ and $\varphi_{F}$ have common range. We can now explicitly relate $V_{F}^{+}$and $V_{S}^{+}$to some multiple of the target market value $M V_{T}$. We denote it $\theta: V_{F}^{+}=V_{S}^{+}=V^{+}=\beta^{-1}\left(p^{-1}\left(\theta M V_{T}\right)\right)$. 


\section{Supplement F - Proposition 1 derivation}

To obtain Equation (7), we start from Equation (6):

$$
\begin{aligned}
& {\left[\varphi_{S}{ }^{\prime}-\left(\varphi_{S} \varphi_{F}\right)^{\prime}\right]\left(B+b M V_{T} \mu_{s}\right)-\left(\varphi_{S} \varphi_{F}\right)^{\prime} L} \\
& -\gamma\left[\left(\varphi_{S}{ }^{\prime}-\left(\varphi_{S} \varphi_{F}\right)^{\prime}\right) \frac{\left(b^{2} M V_{T}^{2} \hat{\sigma}_{s, t}^{2}+\left(B+b M V_{T} \mu_{s}\right)^{2}\right)}{2}+\left(\varphi_{S} \varphi_{F}\right)^{\prime} \frac{L^{2}}{2}\right]=0
\end{aligned}
$$

Using the definition of $\varphi_{S}$ and $\varphi_{F}$ (see Section 1.6), we compute the derivative of $\varphi_{S}$ and $\left(\varphi_{S} \varphi_{F}\right)$ with respect to $v$, the CEO valuation of the target:

$$
\begin{aligned}
& \frac{\partial \varphi_{S}}{\partial v}=\frac{1}{V^{+}-V^{-}}=\frac{1}{\beta^{-1}\left(p^{-1}\left(\theta M V_{T}\right)\right)-\beta^{-1}\left(p^{-1}\left(M V_{T}\right)\right)} . \\
& \frac{\partial\left(\varphi_{S} \varphi_{F}\right)}{\partial v}=\frac{2\left(v-V^{-}\right)}{\left(V^{+}-V^{-}\right)^{2}}=\frac{2\left(v-\beta^{-1}\left(p^{-1}\left(M V_{T}\right)\right)\right)}{\beta^{-1}\left(p^{-1}\left(\theta M V_{T}\right)\right)-\beta^{-1}\left(p^{-1}\left(M V_{T}\right)\right)} .
\end{aligned}
$$

Using equations (F2) and (F3), we solve the CEO's first order condition (Equation (F1)). This results in Proposition 1. 


\section{Supplement G - Positive risk adjusted bonus}

To see that the risk adjusted bonus must be positive at $v^{*}$, note that the probabilities $\varphi_{S}$ and $\varphi_{F}$, estimated at $v^{*}$, must (by definition) be positive. Also note that when $L$ is zero (implying no loss in case of dismissal), Equation (7) implies $v^{*}$ equals to $\left(V^{+}+V^{-}\right) / 2$. This is intuitive since the reservation value should maximize the probability of a successful takeover and not being fired (see Figure 2 - Panel B). However, if $L$ is positive (which we assume), the optimal valuation is below $\left(V^{+}+V^{-}\right) / 2$ (see Figure 2, Panel B) as the derivative of $v^{*}$ with respect to $L$ is negative.

In this region, the derivative of $\varphi_{S}\left(1-\varphi_{F}\right)$ with respect to $v^{*}$ is positive. Computing this derivative and taking into account its positive sign leads to a positive risk adjusted bonus $\left(B+b M V_{T} \mu_{s}-\gamma / 2\left(B+b M V_{T} \mu_{s}\right)^{2}-\gamma / 2 b^{2} M V_{T}^{2} \hat{\sigma}_{s, t}^{2}\right)$ 


\section{Supplement H - Determinants of the CEO valuation}

Expected bonus. We are interested in the sign of $\partial v^{*} / \partial\left(B+b M V_{T} \mu_{s}\right)$. A mechanical application of calculus rules to Equation (7) shows that, as $\left(B+b M V_{T} \mu_{s}\right)$ must be positive (see Section 1.6), the sign of the derivative is determined by the sign of $\left(1-\gamma\left(B+b M V_{T} \mu_{s}\right)\right)$, which is positive if $\left(B+b M V_{T} \mu_{s}\right)<1 / \gamma$. We also know from Section 1.6 that $\left(B+b M V_{T} \mu_{s}\right)-(\gamma / 2)\left(B+b M V_{T} \mu_{s}\right)^{2}$ must be greater than $(\gamma / 2) b^{2} M V_{T}^{2} \hat{\sigma}_{s, t}^{2}$. This second condition translates into $\left(B+b M V_{T} \mu_{s}\right)$ smaller than $(2 / \gamma)-\left(b^{2} M V_{T}^{2} \hat{\sigma}_{s, t}^{2} /\left(B+b M V_{T} \mu_{s}\right)\right)$. These two conditions lead to the situation presented in Figure H.1:

- for $\left(B+b M V_{T} \mu_{s}\right)$ between 0 and $1 / \gamma: \partial v * / \partial\left(B+b M V_{T} \mu_{s}\right)$ is positive. An increase in the expected bonus leads to an increase in the CEO's reservation value.

- for $\left(B+b M V_{T} \mu_{s}\right)$ between $1 / \gamma$ and $(2 / \gamma)-\left(b^{2} M V_{T}^{2} \hat{\sigma}_{s, t}^{2} /\left(B+b M V_{T} \mu_{s}\right)\right)$, the derivative is negative.

Expected bonus variance. The sign of $\partial v^{*} / \partial b^{2} M V_{T}^{2} \hat{\sigma}_{s, t}^{2}$ depends on the sign of the derivatives of $\left(b+b M V_{T} \mu_{s}\right)-(\gamma / 2)\left(b+b M V_{T} \mu_{s}\right)^{2}-(\gamma / 2) b^{2} M V_{T}^{2} \hat{\sigma}_{s, t}^{2}$ with respect to $b^{2} M V_{T}^{2} \hat{\sigma}_{s, t}^{2}$. The risk aversion coefficient $\gamma$ being positive by definition, the sign of $\partial v^{*} / \partial b^{2} M V_{T}^{2} \hat{\sigma}_{s, t}^{2}$ is negative. An increase in the (perceived) variance of the expected bonus leads to a decrease in the CEO's reservation value. 


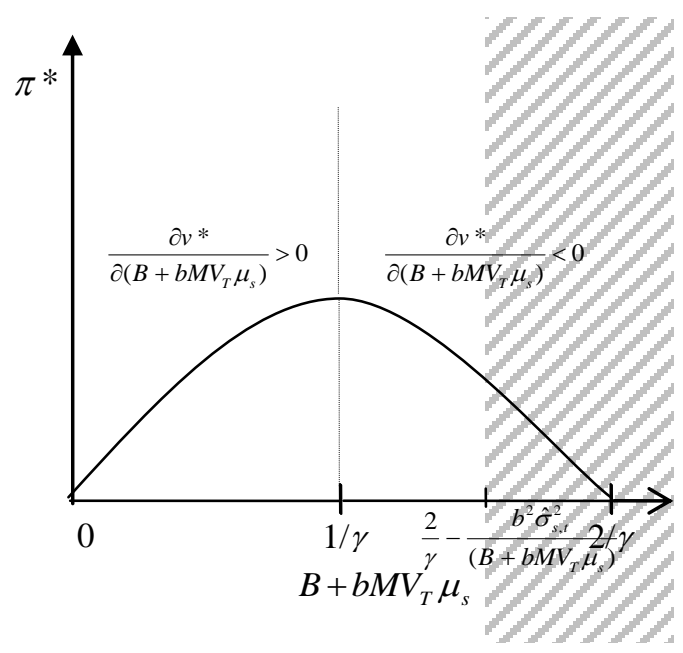

Figure H.1. The CEO's reservation value as a function of the expected bonus. The curve depicted plots the CEO's reservation value with respect to $\left(B+b M V_{T} \mu_{s}\right)$, which is the expected bonus in case of deal completion. The dashed area denotes the zone of inadmissible parameter values. If $\left(B+b M V_{T} \mu_{s}\right)>(2 / \gamma)-\left(\hat{\sigma}_{s, t}^{2} /\left(B+b M V_{T} \mu_{s}\right)\right)$ than some unconditional probability outcomes are negative. 


\section{Supplement I - Proposition 2 derivation}

We first provide intuitive arguments. We then turn to more formal arguments.

\section{Intuition}

In Section I, we showed that learning increases the CEO's valuation (the maximum price he is willing to pay to acquire the target). The learning mechanism is characterized by two important features:

- $\quad$ as learning comes from past acquisitions, it is common knowledge to the bidders: bidders know (or at least have a good idea about) their respective levels of experience;

- learning generates asymmetry: as learning increases valuation (a right-shift of the valuation distribution) and as learning is common knowledge, the more a bidder learns through past acquisitions, everything else equal, the more the valuation distributions between bidders become asymmetric.

So, taking into account asymmetry is a key to understanding the impact of learning on the CEOs bidding behavior and price formation mechanism in the market for corporate control.

The bidding and price determination mechanisms of tender offers and private auctions are respectively the open ascending auction and the sealed-bid first-price auction. In the case of an ascending auction, the auctioneer starts the process at some low price and increases it progressively. Bidders quit the auction as the price rises until only one bidder remains. The last bidder wins the auction and pays the price that prompted the second-to-last bidder to exit. In an ascending auction, the dominant strategy is therefore to bid one's own valuation: by quitting at an inferior price level, the bidder looses the opportunity to make a profitable acquisition but by bidding more, he risks paying more than the target is really worth to him. It is important to emphasize that this is a dominant strategy: it does not depend on the strategy adopted by other bidders. This result holds even in the case of risk aversion, asymmetry and correlation. So, in an ascending auction, the bidding function is increasing in the valuation. The acquisition price, 
conditionally on winning the auction, is the valuation of the second-best bidder. If the bidders' valuations are independent, there is no mechanism that connects the winning bidder's valuation and the price he pays. If, however, bidders' valuations are positively correlated, then an increase in the winning bidder's valuation will be statistically associated with an increase in other bidders' valuations, among which the second-best bidder. In such a case, the price function is increasing in the winning bidder valuation. Note however that if we focus on the expected ex-post observable price, even in the case of independent values, an increase in valuation leads the bidder to win more often and, by this channel, increases the expected ex-post observable price.

Let us now turn to the case of a sealed-bid first price auction. The winning bidder is the one who proposes the highest price and he will pay his bid. The determination of the equilibrium bidding function is based, in this case, on the maximization of the bidder's expected payoff. As shown below, in the case of risk aversion, asymmetry and positively correlated valuation, we obtain (using the framework of Maskin and Riley (2000b)) a set of differential equations that characterizes equilibrium behaviors of bidders. Technical arguments (using the single crossing difference condition and the monotonic selection theorem - see Milgrom (2004)) show that the induced equilibrium bidding function is increasing in the bidders' valuation. As the price paid by the winning bidder is his own bid, the price function (by definition) is also increasing in the (winning) bidder's valuation. In the first price auction however, as emphasized by Arozamena and Cantillon (2004), showing that the bidding function is increasing in valuation is not enough to infer the consequences of change in asymmetry on ex-post observable prices. This is fundamentally due to the fact that optimal bidding strategies of bidders are inter-dependent (they are not dominant strategies). The equilibrium response of rival bidders to a change in asymmetry must therefore be taken into account. Using the results provided by Arozamena and Cantillon (2004), we show below that, for an increase in asymmetry (defined as a right-shift of the bidder valuation distribution), the ex-post observable price conditional on winning the auction contest is increasing in the valuation. 
In direct negotiations, the bidding behavior of the acquirer is influenced by some form of information asymmetry (see Hansen (1987) for an application involving the choice of payment medium). We capture this asymmetry by assuming that the seller's reserve price is unknown to the acquirer. Assuming moreover that the dominant strategy of the acquirer is a first and final offer (see Samuelson (1984) for an analysis of the context in which such a result holds), the equilibrium bidding function of the acquirer can easily be derived. The same technical arguments as used for first-price sealed-bid auctions imply that the bidding function is increasing in the bidder valuation. Since the bidder pays his own bid if accepted by the seller, the price function is (again by definition) increasing in the bidder's valuation. The issue of equilibrium rival bidders' adjustment does not arise here, as there are no such rival bidders and the seller's role is essentially passive.

\section{Proofs of Proposition 2}

\subsection{General Setting}

We analyze the case of 2 CEOs. We assume private valuations (the CEO's valuations obtained from Proposition 1) and risk-averse CEOs (consistent with Section 1). CEO $i$ is the bidder of interest. He has made past acquisitions. CEO $j$ is the rival bidder. We assume that he has not done previous acquisitions. Past acquisitions are common knowledge. They generate learning, which translates into a right-shift of the CEO's valuation distribution (an increase in mean, a direct consequence of Proposition 1). This is a case of conditional stochastic dominance (see Arozamena and Cantillon, 2004, definition 1). 
Valuations are positively correlated. ${ }^{21}$ We denote by $\left.F_{v_{j}^{*}} . \mid v_{i}^{*}\right)$ the distribution of CEO $j$ 's valuation conditional on CEO $i$ 's valuation and assume that it is a continuous and differentiable function. We denote $f_{v_{j}^{*}}\left(. \mid v_{i}^{*}\right)$ the corresponding density function. The positive statistical association between CEO valuations is captured by assuming that $F_{v_{j}^{*}}\left(. \mid v_{i}^{*}\right)$ has increasing differences:

$$
\forall v_{j}^{*+}>v_{j}^{*}, v_{i}^{*_{+}}>v_{i}^{*}: F_{v_{j}^{*}}\left(v_{j}^{*+} \mid v_{i}^{*+}\right)-F_{v_{j}^{*}}\left(v_{j}^{*} \mid v_{i}^{*_{+}}\right) \geq F_{v_{j}^{*}}\left(v_{j}^{*+} \mid v_{i}^{*}\right)-F_{v_{j}^{*}}\left(v_{j}^{*} \mid v_{i}^{*}\right)
$$

This increasing difference condition is equivalent to imposing that $\partial F\left(v_{j}^{*} \mid v_{i}^{*}\right) / \partial v_{j}^{*}$ is increasing in $v_{i}^{*}$. In other words, the higher CEO $i$ 's valuation, the higher the rate at which the CEO $j$ 's valuation is increasing. Conditional stochastic dominance implies first order stochastic dominance (FOSD):

$$
F_{v_{i}^{*}}\left(. v_{j}^{*_{+}}\right)<F_{v_{j}^{*}}\left(. \mid v_{i}^{*^{*}}\right)
$$

This amounts to the assumption that, despite positive correlation between CEOs' valuations, the CEO who implements deals learns more than the CEO who does not.

\section{I.2. Tender Offers (ascending open auction)}

Equilibrium bidding function. By using classical game theory arguments, it is straightforward to show that the dominant strategy for each CEO is to bid up to his own valuation (recall that, in Section 1, we define CEO's valuation as his certainty-equivalent of the target value). The arguments are as follows:

\footnotetext{
${ }^{21}$ Since Milgrom and Weber (1982), the more general concept of affiliation has been introduced in auction theory to deal with statistically interdependent valuations. Positive correlation is a special case of affiliation (see Milgrom (2004), p. 137).
} 
- $\quad$ assume the CEO $i$ chooses a bid $b$ above his own value $v_{i}^{*}$. If he looses the tender offer, his payoff is zero. If he wins, two cases are possible. Either he would also have won by bidding his valuation $v_{i}^{*}$. In such a case, bidding $b$ instead of $v_{i}^{*}$ changes nothing (he wins in the two cases, he pays the same price). Or he wouldn't have won by bidding his valuation $v_{i}^{*}$. In such a case, he has to pay a price greater than his own valuation. He wins but, by the definition of the valuation, he gets a negative payoff;

- $\quad$ assume the CEO $i$ chooses a bid $b$ below his own valuation $v_{i}^{*}$. If CEO $j$ 's bid is such that CEO $i$ wins the tender offer, since the price paid by CEO $i$ is the price level at which CEO $j$ quits, CEO $i$ would have had the same payoff by bidding $v_{i}^{*}$ instead of $b$. But, if the CEO $j$ 's bid is between $b$ and $v_{i}^{*}$, the CEO $i$ will loose the tender offer while he would have won by bidding $v_{i}^{*}$ with a positive payoff. The CEO $i$ is therefore worse off bidding $b$ instead of $v_{i}^{*}$.

Irrespective of asymmetry, risk-aversion and correlated valuations, the equilibrium bidding strategy for bidder $i$ is therefore simply to bid his valuation:

$$
\beta\left(v_{i}^{*}\right)=v_{i}^{*}
$$

Note that this equilibrium bidding strategy is a dominant strategy: it does not depend on the strategy adopted by rival bidders. Thus, we do not have to incorporate in our static analysis potential optimal responses of rival bidders to a change of bidder $i$ valuation. The equilibrium bidding function is clearly increasing in the CEO's valuation. ${ }^{22}$

\footnotetext{
${ }^{22}$ Note that, even if the arguments developed here are the same as those used to prove the equivalence between the ascending open auction and the second-best price auction in an independent private value setup, this strategic equivalence does not extend to the case of $\mathrm{N}$ bidders with correlated valuations.
} 
Expected ex-post observable price. The ex-post observable price is the price paid by the winner of the tender offer. To obtain its expected value, we have to integrate it over the valuation distribution of the losing bidder. In the open ascending auction setup with two acquirers, it is the average bid (or valuation) of the loosing acquirer:

$$
E\left[p\left(v_{i}^{*} \mid v_{j}^{*}<v_{i}^{*}\right)\right]=\int_{V^{-}}^{v_{i}^{*}} v_{j}^{*} f_{v_{j}^{*}}\left(v_{j}^{*} \mid v_{i}^{*}\right) d v_{j}^{*}
$$

Where $p$ stands for ex-post price. Note that, using Equation (I.3), this is equivalent to:

$$
E\left[p\left(\beta\left(v_{i}^{*}\right) \mid \beta\left(v_{j}^{*}\right)<\beta\left(v_{i}^{*}\right)\right)\right]=\int_{\beta\left(V^{-}\right)}^{\beta\left(v_{i}^{*}\right)} \beta\left(v_{j}^{*}\right) f_{\beta\left(v_{j}^{*}\right)}\left(\beta\left(v_{j}^{*}\right) \mid \beta\left(v_{i}^{*}\right)\right) d \beta\left(v_{j}^{*}\right) .
$$

Learning. Learning increases the CEO valuation (see Proposition 1). Using the Leibniz theorem, the derivative of the price function with respect to the CEO $i$ valuation $v_{i}^{*}$ is:

$$
\frac{\partial E\left[p\left(v_{i}^{*} \mid v_{j}^{*}<v_{i}^{*}\right)\right]}{\partial v_{i}^{*}}=v_{i}^{*} f_{v_{j}^{*}}\left(v_{i}^{*} \mid v_{i}^{*}\right)+\int_{V^{-}}^{v_{i}^{*}} \frac{d v_{j}^{*} f_{v_{j}^{*}}\left(v_{j}^{*} \mid v_{i}^{*}\right)}{d v_{i}^{*}} d v_{j}^{*}
$$

By the increasing differences property of $F\left(v_{j}^{*} \mid v_{i}^{*}\right)$ (see Equation (I.1)), the derivative of the price function with respect to CEO $i$ 's valuation $v_{i}^{*}$ is therefore positive: the ex-post observable price is an increasing function of the CEO's valuation. It is interesting to note this average ex-post observable price increase is obtained by summing two effects:

- $\int_{V^{-}}^{v_{i}^{*}} \frac{d v_{j}^{*} f_{v_{j}^{*}}\left(v_{j}^{*} \mid v_{i}^{*}\right)}{d v_{i}^{*}} d v_{j}^{*}:$ this effect is due to the increasing differences property of $F_{v_{j}^{*}}\left(\cdot v_{i}^{*}\right)$. Without a positive correlation between bidders' valuations, it would have been equal to zero.

Milgrom and Weber (1982) show how to model the dominant strategy in an ascending auction in such a framework. 
- $\quad v_{i}^{*} f_{v_{j}^{*}}\left(v_{i}^{*} \mid v_{i}^{*}\right):$ this effect represents new states of the world in which bidder $i$ wins the auction, paying however a higher price.

\section{I.3. Private Auctions}

We now turn to the case of private auctions organized by financial intermediaries. Hansen (2001) provides an in-depth presentation of the institutional setting of such auctions. The key feature for our analysis is that these are usually sealed bid first-price auctions. They are very different from open ascending auctions. The first question that we analyze here, as in the case of the second price auction, is whether bids and price are strictly increasing in valuation as in the tender offers setup. A complication however arises from the fact that the equilibrium bidding strategies are interdependent. Our static analysis (the effect of learning on average ex-post observable prices) must therefore account the strategic behavior adjustments of rival bidders.

Equilibrium bidding function. Asymmetric first price auctions are analyzed in Maskin and Riley (2000b). Arozamena and Cantillon (2004) extend the set of available results by providing a static analysis at equilibrium of asymmetry in procurement auctions context. Their results rely on conditional stochastic dominance of the cost distributions of bidders (the equivalent of Equation I. 2 but stated in a procurement auctions context). As we limit ourselves to the case of two bidders, in the terminology of Maskin and Riley (2000b), bidder $i$ is the strong bidder and bidder $j$ is the weak bidder.

Maskin and Riley (2000b) do not explicitly deal with risk aversion and interdependence. However, assuming that the CEOs utility functions are log supermodular ${ }^{23}$ and considering the interdependence between valuations and the private nature of valuations, Proposition 5 of Maskin

23 In a private-value setup, log supermodularity imposes the following restriction: $\partial^{2} \log \pi_{i}\left(b, v_{i}^{*}\right) / \partial b \partial v_{i}^{*} \geq 0$, where $\pi_{i}\left(b, v_{i}^{*}\right)$ is the CEO $i$ expected surplus. 
and Riley (2000a) establishes the existence of a pure strategy Bayesian Nash equilibrium in a first-price auction. As pointed out by the authors, sufficient conditions for the $\log$ supermodularity of the utility function are that preferences are monotonic and exhibit either risk aversion or risk neutrality. Risk aversion is assumed here and monotonic preferences are by construction since the CEO's valuation is obtained by maximizing his expected utility (Section 1.4). Note also that Arozamena and Cantillon (2004) clearly state that their results hold also under risk aversion and that, as long as the conditional stochastic dominance condition is fulfilled (assumed here at Equation (1.2), consistently with respect to Propositon 1), their result remains valid.

Following Maskin and Riley (2000b), denote by $\pi_{i}\left(b, v_{i}^{*}\right)$ CEO i's expected surplus when he bids $b$ and has valuation $v_{i}^{*}$. The CEO $i$ decision problem is then:

$$
\begin{aligned}
& \underset{b}{\operatorname{Max}} \pi\left(b, v_{i}^{*}\right) \\
& =\underset{b}{\operatorname{Max}} U_{i}\left(v_{i}^{*}-b\right) \operatorname{Pr}\left(v_{j}^{*}<\beta_{j}^{-1}(b) \mid v_{i}^{*}\right) \text {. } \\
& =\underset{b}{\operatorname{Max}} U_{i}\left(v_{i}^{*}-b\right) F_{v_{j}^{*}}\left(\beta_{j}^{-1}(b) \mid v_{i}^{*}\right)
\end{aligned}
$$

We first take the log to obtain:

$$
\underset{b}{\operatorname{Max}} \log \pi\left(b, v_{i}^{*}\right)=\underset{b}{\operatorname{Max}}\left\lfloor\log \left(U_{i}\left(v_{i}^{*}-b\right)\right)+\log \left(F_{v_{j}^{*}}\left(\beta_{j}^{-1}(b) \mid v_{i}^{*}\right)\right)\right\rfloor,
$$

and then differentiate with respect to $b$ to obtain the following first order condition:

$$
\frac{-U_{i}{ }^{\prime}\left(v_{i}^{*}-b\right)}{U_{i}\left(v_{i}^{*}-b\right)}+\frac{f_{v_{j}^{*}}\left(\beta_{j}^{-1}(b) \mid v_{i}^{*}\right)}{F_{v_{j}^{*}}\left(\beta_{j}^{-1}(b) \mid v_{i}^{*}\right) \beta_{j}\left(v_{j}^{*}\right)^{\prime}}=0 .
$$

Applying the same development to $\mathrm{CEO} j$, we obtain the characterization of the equilibrium bidding functions in our setup (the equivalent of Equation (3.12) in Maskin and Riley (2000b) ${ }^{24}$ ): for CEO $i$ (strong bidder):

\footnotetext{
${ }^{24}$ The boundary conditions emanating from the common range argument (equation (3.13) in Maskin and Riley (2000b)) apply also in our setup.
} 


$$
\frac{f_{v_{j}^{*}}\left(\beta_{j}^{-1}(b) \mid v_{i}^{*}\right)}{F_{v_{j}^{*}}\left(\beta_{j}^{-1}(b) \mid v_{i}^{*}\right) \beta_{j}\left(v_{j}^{*}\right)^{\prime}}=\frac{U_{i}^{\prime}\left(v_{i}^{*}-b\right)}{U_{i}\left(v_{i}^{*}-b\right)}
$$

for CEO $j$ (weak bidder):

$$
\frac{f_{v_{i}^{*}}\left(\beta_{i}^{-1}(b) \mid v_{j}^{*}\right)}{F_{v_{i}^{*}}\left(\beta_{i}^{-1}(b) \mid v_{j}^{*}\right) \beta_{i}\left(v_{i}^{*}\right)^{\prime}}=\frac{U_{j}{ }^{\prime}\left(v_{j}^{*}-b\right)}{U_{j}\left(v_{j}^{*}-b\right)}
$$

Equation (I.9) characterizes the equilibrium bidding functions of CEO $i$ and CEO $j$. To ascertain whether they are increasing in their respective reservation values, one can appeal to the monotonic selection theorem (Milgrom (2004), Theorem (4.1)). Assuming log supermodular utility, the expected surplus function $\pi_{i}\left(b, v_{i}^{*}\right)$ satisfies the strict single crossing difference conditions. ${ }^{25}$ Therefore, by monotonic selection, the CEOs' equilibrium bidding functions $\beta_{i}\left(v_{i}^{*}\right)$ and $\beta_{j}\left(v_{j}^{*}\right)$ must be non-decreasing in their respective valuations. It remains to be proved that they are strictly increasing.

Assume the contrary. Then, there would exist a range of reservation values $v_{i}^{*}$ for which CEOs would offer a constant bid $b$;

- with some probability, ties would occur. ${ }^{26}$ In case of ties, each of the two CEOs could win with probability one instead of probability $1 / 2$ by increasing their bid by a small amount $\varepsilon$. Since $\varepsilon$ (the cost of increasing the bid) can be arbitrarily small, it would always be profitable to increase the bid.

\footnotetext{
${ }^{25}$ To see this, note that $\left(\partial^{2} \log \pi_{i}\left(b, v_{i}^{*}\right) / \partial b \partial v_{i}^{*}\right) \geq 0$, which is the constraint imposed by the $\log$ supermodularity assumption in a private value setup, is one of the sufficient conditions to insure that the single crossing difference condition is fulfilled (see Milgrom (2004), p. 100, condition (ii)).

${ }^{26}$ With continuous support of the reservation valuations, the probability of ties $\left(v_{i}^{*}=v_{j}^{*}\right)$ is zero but the probability that the valuations fall in the same range is strictly higher than zero.
} 
- ties are therefore incompatible with the equilibrium and the equilibrium bidding functions must be strictly increasing in the CEOs reservation values.

Expected ex-post observable price. Denote, as in Arozamena and Cantillon (2004) ${ }^{27}$, $p r_{i}^{E}(b)$ the probability that bidder $i$ (the strong bidder) will bid below $b$ in equilibrium (computed using $F_{v_{i}^{*}}\left(. \mid v_{j}^{*}\right)$ ) and $\operatorname{pr}_{j}^{E}(b)$ the corresponding probability that bidder $j$ (the weak bidder) will bid bellow $b$ in equilibrium. The ex-post observable price conditional on winning for bidder $i$ is:

$$
p\left(b_{j} \mid b_{j}<b_{i}\right)=\int_{b_{j}}^{\infty} b_{i} d p r_{i}^{E}\left(b_{i}\right)
$$

The expected ex-post observable price conditional on winning for bidder $i$ is therefore:

$$
E\left[p\left(b_{j} \mid b_{j}<b_{i}\right)\right]=\int_{0}^{\infty}\left[\int_{b_{j}}^{\infty} b_{i} d p r_{i}^{E}\left(b_{i}\right)\right] b_{j} d p r_{j}^{E}\left(b_{j}\right)=\int_{0}^{\infty} p r_{j}^{E}\left(b_{i}\right) b_{i} d p r_{i}^{E}\left(b_{i}\right)
$$

Equation (I.11) highlights that the expected ex-post price of the winning bidder aggregates two effects:

- $\quad$ the probability of winning: $p r_{j}^{E}\left(b_{i}\right)$;

- the price paid conditional on winning: $\int_{b_{j}}^{\infty} b_{i} d p r_{i}^{E}\left(b_{i}\right)$.

Learning. Learning means, in our setup, a right-shift of the CEO valuation distribution. Let us denote $\tilde{F}_{v_{i}^{*}}\left(. v_{j}^{*}\right)$ the valuation distribution of CEO $i$ after one more acquisition. By conditional stochastic dominance, $\tilde{F}_{v_{i}^{*}}\left(v \mid v_{j}^{*}\right)<F_{v_{i}^{*}}\left(v \mid v_{j}^{*}\right)$ for all $v$. Proposition 1 in Arozamena and Cantillon (2004) establishes that $\tilde{p} r_{i}^{E}(b)<p r_{i}^{E}(b)$ : the equilibrium bidding distribution of

\footnotetext{
${ }^{27}$ We add the $E$ superscript to emphasize that we are dealing with equilibrium bid distribution.
} 
the bidder who learns (and valuation increases) shift to the right. He bids more aggressively in equilibrium. This central result shows us by FOSD that, in equilibrium:

$$
\int_{b_{j}}^{\infty} b_{i} d \widetilde{p} r_{i}^{E}\left(b_{i}\right)<\int_{b_{j}}^{\infty} b_{i} d p r_{i}^{E}\left(b_{i}\right)
$$

Everything else constant, in equilibrium, learning decreases the probability of an ex-post observable low price:

$$
\int_{0}^{\infty} p r_{j}^{E}\left(b_{i}\right) b_{i} d \bar{p} r_{i}^{E}\left(b_{i}\right)<\int_{0}^{\infty} p r_{j}^{E}\left(b_{i}\right) b_{i} d p r_{i}^{E}\left(b_{i}\right) .
$$

\section{I.3. Direct Negotiation}

Direct negotiations involve bargaining between a single acquirer and a single target. As pointed out in the introduction of Section 2, direct negotiations between parties are frequent in merger deals. Samuelson (1984) studies optimal bargaining with information asymmetry. He shows that a bidder facing informational asymmetry about the value of the good, will find it optimal to make a first and final offer. Hansen (1987) uses this insight to investigate the role of the payment medium in the context of M\&As. We use here the same setup to explore bidding behavior (and the ex-post observable price consequences) of the CEO.

Assuming that it is optimal for the acquiring CEO to make a first and final offer, we still need to worry about the source of information asymmetry. It seems natural to presume that the acquiring CEO is uncertain about the target shareholders' reserve price. We denote the distribution of the target shareholders' reserve price by $F\left(r \mid v_{i}^{*}\right)$, using intentionally the same notation as for the distribution of competitors' valuations in the two previous auction contexts discussed above.

Equilibrium bidding function. In such a setup, the acquiring CEO $i$ maximizes: 


$$
\begin{aligned}
& \underset{b}{\operatorname{Max}} \pi\left(v_{i}^{*}-b\right) \\
= & \operatorname{Max}_{b} U_{i}\left(v_{i}^{*}-b\right) F\left(b \mid v_{i}^{*}\right)
\end{aligned}
$$

As with sealed-bid first price auctions, taking the log and writing the first-order condition, we obtain the equation characterizing the optimal CEO $i$ bid:

$$
\frac{U_{i}^{\prime}\left(v_{i}^{*}-b\right)}{U_{i}\left(v_{i}^{*}-b\right)}=\frac{f\left(b \mid v_{i}^{*}\right)}{F\left(b \mid v_{i}^{*}\right)} \text {. }
$$

The same arguments used in the case of sealed-bid first-price auctions still hold. The utility function is assumed to be log supermodular. The CEO expected surplus therefore satisfies the single crossing difference conditions. By monotonic selection, the CEO optimal bidding function is non-decreasing in his valuation. Only the arguments used to prove the strictly increasing behavior of the optimal bidding function change. The intuition is as follows:

- assume the optimal bidding function is not strictly increasing. Then, there would exist a range of valuations $v_{i}^{*}$ for which CEOs would offer a constant bid $b$;

- but, over this range of constant bids, the probability of doing the deal is constant while $v_{i}^{*}$ is increasing. So, increasing by some $\varepsilon$ the bid would be like buying partial insurance providing a higher probably of succeed in the deal. Since risk averse decision makers value positively insurance contracts, such a decision would have a positive impact on the expected surplus of the CEO.

- $\quad$ this is incompatible with optimality. The CEO bidding function must therefore be strictly increasing in $v_{i}^{*}$.

Learning and expected payment conditional on winning. There is only one active bidder. Consequently, there is no rival bidder from whom an equilibrium strategic adjustment should be taken into account. It is enough to see that:

- $\quad$ optimal bids are increasing in $v_{i}^{*}$; 
- the ex-post observable acquisition price (the price conditional on a successful deal attempt) is the acquirer's bid.

Arozamena, Leandro, Cantillon, Estelle, 2004, Investment Incentives in Procurement Auctions, Review of Economic Studies 71, 1-18

Hansen, Robert G., 1987, A theory for the choice of exchange medium in mergers and acquisitions, Journal of Business 60, 75-95.

Maskin, Eric, and John Riley, 2000a, Equilibrium in sealed high bid auctions, Review of Economic Studies 67, 439-454.

Maskin, Eric, and Johan Riley, 2000b, Asymmetric auctions, Review of Economic Studies 67, 413-438.

Milgrom, Paul R., and Robert J. Weber, 1982, A theory of auctions and competitive bidding, Econometrica 50, 1089-1122.

Milgrom, Paul R., 2004, Putting auction theory to work, Cambridge University Press.

Samuelson, William, 1984, Bargaining under asymmetric information, Econometrica 52, 9951006. 


\section{Supplement J - Empirical issues}

\section{The acquisition program effect}

Schipper and Thompson (1983) and Malatesta and Thompson (1985) emphasize that the market reaction at the start of an acquisition program capitalize the anticipated wealth effects of the whole program, not just that of the current single acquisition. Hence market reactions to subsequent deal announcements are merely revisions of the initial anticipation and are affected only by the incremental information content. This acquisition program anticipation effect does not suggest any particular trend in the observed CAR from deal to deal (except that the CAR for the first deal should be larger - at least in absolute value - since it contains more information.) So, if we adhere to the acquisition program anticipation effect, predictions about the CAR from deal to deal must be understood as predictions about the trend of anticipations revisions rather than about the trend of wealth effects per se.

\section{Ex-post Sample Selection Biases}

Although we have derived clear empirical implications of learning and hubris in Proposition 3, empirical tests of the above predictions are subject to important difficulties. Two of the most important are likely to be sample selection biases and errors-in-variables.

Roll (1986) describes the potential impact of the winner's curse and hubris on the ex-post observed abnormal returns. Our analysis suggests a second sample selection phenomenon; viz., we do not observe deals that would have been undertaken by dismissed CEOs. These two biases work in opposite directions:

- $\quad$ as explained in Roll (1986), hubris-infected CEOs overbid and are subject to the winner's curse. Since we observe mainly those who consummate deals, we most probably observe a disproportionate number of over-optimistic CEOs. 
- conversely, CEOs who pay too much for targets are more likely to be fired. Hence, a disproportionate number of surviving CEO's are less likely to be hubris infected.

Which of these two biases dominates? The answer to this empirical question depends, inter $a l i a$, on the pressure of corporate control mechanisms (the convexity of $\varphi_{S} \varphi_{F}$ in Section 1) and on the strength of hubris (the amplitude of the difference $\hat{\mu}_{0, s}-\mu_{s}$ ).

\section{Errors-in-variable issues}

Figure 3 - Panels A and C reveal an errors-in-variable problem. The sub-sample of acquisition programs characterized by an initial positive CAR should include both rational CEOs (Panel A) and hubris-infected CEOs (Panel C). This mixture will weaken the ex-post empirically observable consequences of learning, as the ex-post observable trend of CAR and BTD will depend on the relative proportion of rational and hubris-infected CEOs. Only the use of some exogenous instrument to identify hubris-infected CEOs could completely resolve this problem.

A final comment: As highlighted in Panel C of Figure 3, the CAR for hubris-infected CEOs may be positive at the beginning of the M\&A program. Then, if instead of learning, CEOs become subject to even more hubris, one might observe the same patterns as in Panel A (for learning rational CEOs), but most probably with a smaller or even negative CAR. Therefore, what is really unique to our learning setup are predictions of Panel B and C. They can not be generated by growing hubris or a shrinking investment opportunity set. The key to an empirical test is therefore to identify a subsample of CEOs that (i) destroy wealth at the first deal and (ii) are most likely hubris infected. 